\title{
TITLE:
}

\section{Damage sequence and safety margin assessment of expansion joints by shake table testing}

\section{$\operatorname{AUTHOR}(S):$}

Otsuki, Yu; Kurata, Masahiro; Skalomenos, Konstantinos A.; Ikeda, Yoshiki

\section{CITATION:}

Otsuki, Yu ... [et al]. Damage sequence and safety margin assessment of expansion joints by shake table testing. Earthquake Engineering and Structural Dynamics 2019, 48(1): 3-26

\section{ISSUE DATE:}

2019-1

URL:

http://hdl.handle.net/2433/242243

\section{RIGHT:}

This is the peer reviewed version of the following article: Yu Otsuki Masahiro Kurata Konstantinos A. Skalomenos Yoshiki Ikeda, Damage sequence and safety margin assessment of expansion joints by shake table testing, Earthquake Engineering and Structural Dynamics, 48(1) 3-26, which has been published in final form at

https://doi.org/10.1002/ege.3120. This article may be used for non-commercial purposes in accordance with Wiley

Terms and Conditions for Use of Self-Archived Versions.; The full-text file will be made open to the public on 06 December 2019 in accordance with publisher's 'Terms and Conditions for Self-Archiving' / 


\title{
DAMAGE SEQUENCE AND SAFETY MARGIN ASSESSMENT OF EXPANSION JOINTS BY SHAKE TABLE TESTING
}

\author{
Yu Otsuki ${ }^{1}$, Masahiro Kurata ${ }^{2}$, Konstantinos A. Skalomenos ${ }^{2}$, and Yoshiki Ikeda ${ }^{2}$ \\ ${ }^{1}$ Graduate School of Engineering, Kyoto University, Kyoto-shi, Kyoto, 615-8530, Japan, \\ otsuki.yu.65n@st.kyoto-u.ac.jp, corresponding author \\ ${ }^{2}$ Disaster Prevention Research Institute, Kyoto University
}

\begin{abstract}
SUMMARY
The performance of non-structural components has attracted attention, and previous large earthquakes have resulted in widespread damage to expansion joints. In contrast to the main structural components, for which ductility beyond the design tolerance is ensured, the safety margin of non-structural components classified as the product of mechanical engineering, such as expansion joints, is uncertain. This paper investigates the damage sequence and safety margin of expansion joints through shake table testing. The expansion joints were installed to connect two rigid steel frames with short and long natural periods. Four commonly used types, high- and standard-performance floor and wall expansion joints, were tested. Seven damage patterns of the four expansion joints were observed, and most of the damage patterns were considered displacement dependent. The damage mechanisms and relative displacements at the moment of damage were identified by using strain gauges attached near collision and damage locations. The high-performance expansion joints showed only minor damage beyond the design motion range, whereas the standard-performance expansion joints exhibited minor damage below the design motion range and failure at the design motion range or slightly beyond. For each damage state, repair information was obtained through a questionnaire to an expansion joint manufacturer, and the sum of the initial cost and repair cost for high- and standard-performance expansion joints was compared. The results will be useful for the selection of expansion joints in the design process.
\end{abstract}

Keywords: expansion joints, non-structural components, shake table test, relative displacement, adjacent buildings

\section{INTRODUCTION}

Building complexes, such as large medical centers or urban redevelopment districts, offer multiple functions and services with interconnected buildings. Each building possesses a unique functionality and is often connected to adjacent buildings by corridors or sky bridges using expansion joints. For base-isolated buildings, expansion joints are also indispensable to cover the large clearance between a base-isolated building and the surrounding ground walls. The function of expansion joints is to allow people to pass over the clearance and to follow the deformation between two buildings during excitations. As the number of urban cities and base-isolated buildings are increasing worldwide, expansion joints are becoming more widely used. These building complexes accommodate hundreds or thousands of people, and thus their safe evacuation or re-occupancy after seismic events is a source of concern. The performance of non-structural components has drawn attention in this context because severe damage to expansion joints also hinders evacuation and building use, and at worst, the failure (i.e., falling) of expansion joints may injure people. Therefore, expansion joints can be considered a critical non-structural component.

Expansion joints have been viewed as breakable components. Several damage cases of expansion joints have been reported after recent earthquakes in Japan. In the 2011 Tohoku earthquake, 90 of 327 expansion joints at isolated buildings were damaged [Kasai et al 2013]. In the 2016 Kumamoto earthquake, severe damage to expansion joints at apartment buildings was observed, including expansion joints that fell down [NILIM and BRI 2013]. Under severe shaking, signs of seismic pounding between adjacent buildings have been observed, along with damage to expansion joints [Bertero et al 1986, Filiatrault et al 1994, Kasai et al 1997, PWRI 1997, and Cole et al 2012]. Similar to other non-structural components, expansion joints are mechanical products, and they are not designed with the ductility-based approach applied to the main structural components. Thus, their safety margins and damage sequences beyond design tolerances have not been quantified.

Decision-making regarding the continuity of building use and the repair plan after an earthquake depends on the extent of damage to structural members as well as to non-structural members. Considering the large repair costs for non-structural components, seismic performance evaluation of non-structural members is essential for risk assessment of buildings. For risk assessment, the Federal Emergency Management Agency (FEMA) [FEMA 2012] provides a database for hundreds of nonstructural components regarding damage descriptions, fragility functions, and required cost, time and procedures for recovery. The FEMA database is mainly based on careful observations of a series of damage patterns in experimental laboratories and in past earthquakes. However, the FEMA database does not include information for expansion joints.

While several studies have focused on expansion joints for bridges [Malhotra 1998, Ni et al 2007, Bi et al 2010, McCarthy et al 2014, and Sun et al 2016], little research is available on expansion joints for buildings, and the deformation mechanisms of expansion joints are different for bridges and buildings. Kasai et al. [2013] investigated 90 damage patterns of expansion joints installed on base-isolated buildings after the 2011 Tohoku earthquake and classified the causes of damage into the following five categories: 1) insufficient consideration of dynamic and cyclic behavior, 2) unintended contact with other elements, 3) construction detail, 4) strength and deformation capacity, and 5) multi-axis movement. The National Institute for Land and Infrastructure Management and the Building Research Institute in Japan [2012] estimated the displacement response of damaged expansion joints during the Tohoku earthquake by accelerometers. Takabatake et al. [2014] examined a possible solution for mitigating damage to adjacent buildings caused by seismic pounding by inserting a soft shock-absorbing material into expansion joints. Damage observations of expansion joints after an earthquake are valuable, but their seismic behaviors and damage scenarios, especially beyond the designed motion range during shaking, remain unknown. In the absence of 
measurement instruments, it is difficult to quantitatively assess the relationship between inputs and damage as well as the safety margin beyond the design tolerance. Therefore, there is a need to investigate the damage mechanisms of expansion joints in sophisticated laboratory testing with measurement systems.

The purpose of the present study is to investigate the damage patterns and mechanisms of expansion joints with measurements based on a series of shaking table tests. Shaking table tests are necessary because damage to expansion joints depends on dynamic behavior, as noted previously by Kasai et al [2013]. Four commonly used types of expansion joints were tested. First, the behavior of the expansion joints was observed under earthquake ground motion, and then the damage mechanism was examined by inputting sine waves repeatedly with increasing amplitude until failure. The damage patterns and mechanisms were investigated by using displacement sensors and strain gauges. The observed damage patterns were described based on the measured critical relative displacement and applied force to expansion joints. For each damage state, repair information was acquired with the cooperation of an expansion joint manufacturer. The obtained results offer a basis for the selection of appropriate expansion joints in the design procedure.

\section{EXPERIMENTAL PLAN}

\subsection{Clearance and motion range of expansion joints}

The important design parameters for expansion joints are clearance and motion range. This research focuses on "seismic" expansion joints designed to sustain large deformation, and expansion joints for thermal expansion and contraction are not considered. As shown in Figure 1(A), expansion joints are commonly installed between two buildings, and the distance between two buildings is defined as the clearance. The motion range is defined for each of the two horizontal directions as the length that an expansion joint can move. The motion range depends on the deformation mechanism and typically varies by 30 to $80 \%$ of the clearance [JEJA 2016]. In catalogues for expansion joints, manufacturers provide a nominal design motion range that contains or does not contain some extent of safety margins (i.e., the nominal design motion range is equal to or smaller than the deformation that the expansion joints can accommodate). Therefore, even with the same nominal design motion range, the safety margin differs for each manufacturer and each type of expansion joint.

Figure 1(B) describes the typical design flow of the motion range in practice. The greatest concern for a structural designer in the design of adjacent buildings is to avoid a collision between two buildings during an earthquake. Therefore, in the first design step, the seismic response of the two buildings against a target seismic hazard is calculated. Several codes prescribe a minimum separation distance between the two buildings and provide simplified calculation methods against target seismic hazards [BCJ 2008, ICBO 1997, CEN 2005, and TBC 1997]. Then, the clearance between the two buildings is determined by taking into account a safety factor selected by the designer and owner of the buildings. Finally, the designer selects expansion joints that fit the clearance. The design flow is straightforward, but when the ratio of the motion range to the clearance is smaller than the reciprocal of the safety factor, there is a possibility of damage to the expansion joints, even against code-level ground motions.

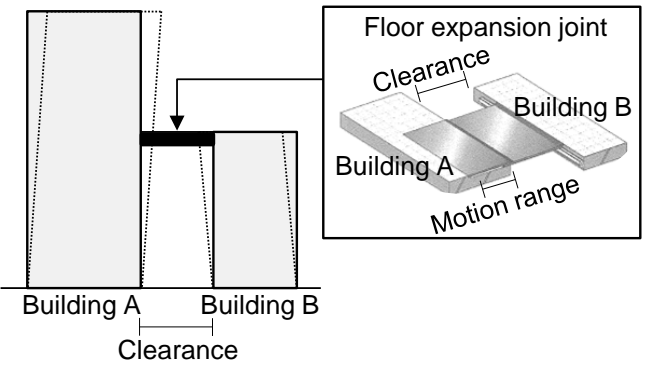

(A)

\begin{tabular}{|c|c|c|c|c|c|c|}
\hline (1) & & (2) & & (3) & & (4) \\
\hline $\begin{array}{l}\text { Minimum Separation } \\
\text { Distance }\end{array}$ & $\times$ & & $=$ & Clearance & $\geqq$ & $\begin{array}{l}\text { Motion Range of } \\
\text { Expansion Joint }\end{array}$ \\
\hline $\begin{array}{l}\text { Time history analysis } \\
\text { - Spectra response analysi }\end{array}$ & \multicolumn{3}{|c|}{$\begin{array}{l}\text { Depending on } \\
\text { designer and owner }\end{array}$} & & & $\begin{array}{l}\text { Mostly } 20 \sim 80 \% \\
\text { of clearance }\end{array}$ \\
\hline
\end{tabular}

(B)

FIGURE 1 Description of clearance and motion range: (A) definition [JSSI 2013]; (B) design flow of motion range

\subsection{Test setup}

A series of shaking table tests for expansion joints were conducted at the Disaster Prevention Research Institute (DPRI) at Kyoto University [DPRI 2018]. Damage to expansion joints depends on the dynamic behavior of the two buildings, and thus two frames connected with expansion joints were prepared. To induce damage to the expansion joints, a large relative displacement beyond the design motion range of the expansion joints must be applied, and this was achieved by making the natural periods of the two frames different. One frame used spherical sliding bearings (SSBs) to simulate the behavior of a long-period structure and accommodate large displacement, and the other frame used rubber bearings to simulate the behavior of a short-period structure.

Figure 2(A)-(B) illustrate the setup, which consisted of two steel frames connected with floor and wall expansion joints, as described in Section 3. The two steel frames were called the short-period frame and long-period frame. The short-period frame was equipped with four rubber bearings and a steel plate mass of $20.6 \mathrm{kN}$ and had a natural period of $0.46 \mathrm{~s}$. The long-period frame used four SSBs and had a natural period of $6.0 \mathrm{~s}$, as determined by the radius of the concave plates of the SSBs [Ponzo et al 2017]. The mass of the long-period frame was $66.7 \mathrm{kN}$ to provide sufficient surface pressure to the SSBs. The height and width of both frames were $235 \mathrm{~cm}$ and $225 \mathrm{~cm}$, respectively. The distance between the two frames was $50 \mathrm{~cm}$. The floor expansion joint was installed on the top of frames to facilitate damage observation, and the two ends were rigidly connected to the top beams. The two ends of the wall expansion joint were connected to the columns of the two frames. 


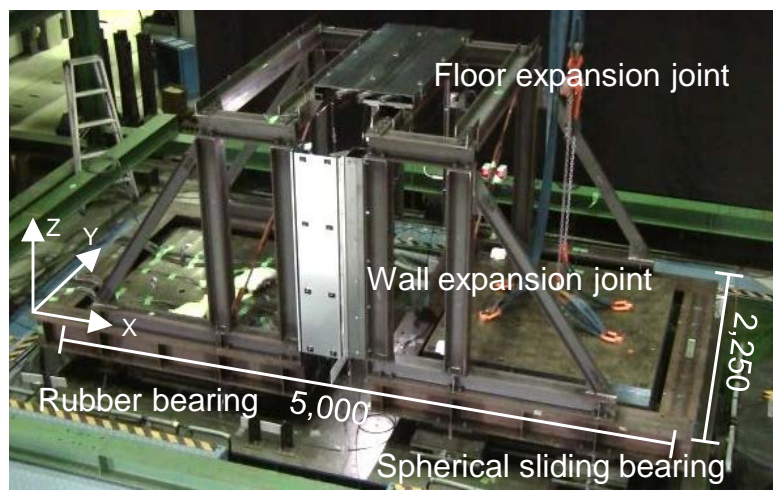

(A)

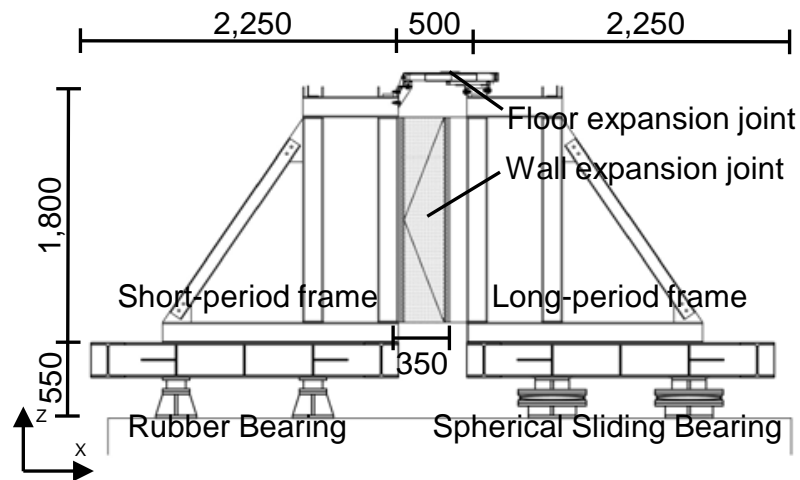

(B)

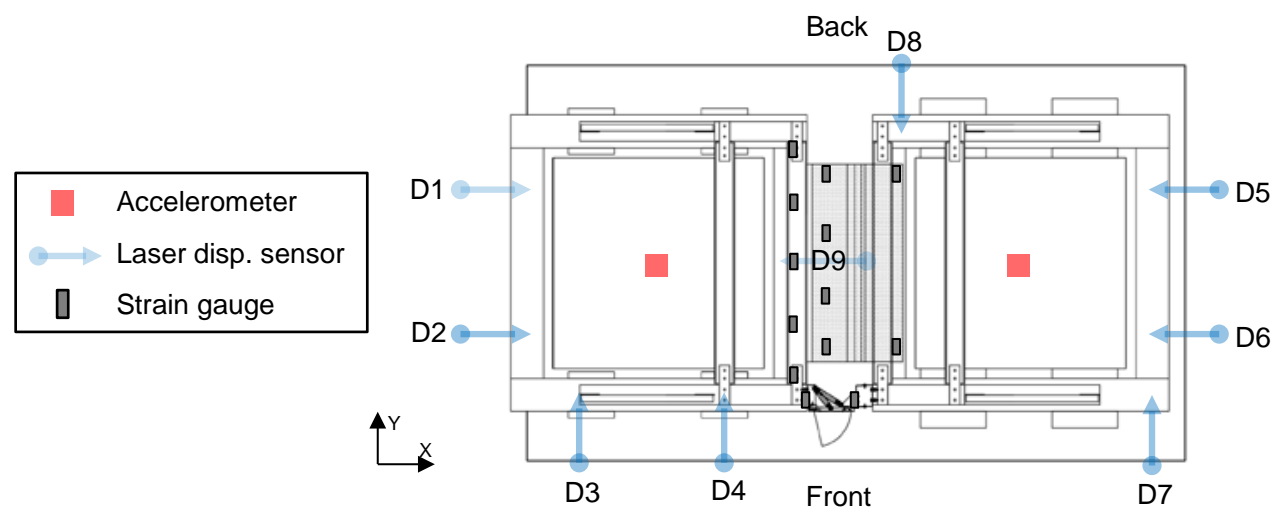

(C)

FIGURE 2 Setup (unit: mm): (A) front view, (B) elevation, and (C) sensor location

\subsection{Measurement}

The test setup was equipped with accelerometers, laser displacement sensors, and strain gauges for measurement with a sampling frequency of $100 \mathrm{~Hz}$. Figure 2(C) shows the locations of the accelerometers, displacement sensors, and some of strain gauges. A total of nine laser displacement transducers were placed at a height of $50 \mathrm{~cm}$ above the shaking table surface. Eight transducers, D1-D8, oriented in the X- and Y-directions were installed at the edge of each frame to monitor rotational motions. D9 measured the relative displacement between the frames. The accelerometers were used to compute the inertial force applied to the frames.

Ten to twenty strain gauges were attached to each expansion joint to detect the exact moment of damage occurrence. The locations were carefully determined by assuming in advance the locations of collision and damage so that the peak response corresponding to collision and damage could be observed in the strain histories.

\subsection{Loading}

The specimens were loaded only in the X-direction to carefully observe the mechanism of failure. Investigations in the drawing of the specimens and discussions with an expansion joint manufacturer prior to the test suggested little effect of coupling on the expected damage mechanism. The deformation mechanisms of the expansion joints were designed essentially to accommodate deformation independently in the tri-axes, i.e., X, Y and Z. First, the dynamic behavior of the specimens within the design motion range was investigated using ground motions. Since damage to expansion joints could be displacementsensitive or acceleration-sensitive, we selected ground motions which have a large spectral value for acceleration and displacement at the natural periods of the tested frames, $0.46 \mathrm{~s}$ and $6.0 \mathrm{~s}$. The selected ground motions are the Mashiki EW recorded under the 2016 Kumamoto earthquake [NIED 2018], the JMA Kobe NS recorded under the 1995 Kobe earthquake [JMA 2018], and an artificial ground motion called BCJ-L2 [BCJ 2018]. These ground motions were scaled down accordingly. The acceleration records and response spectra with $2 \%$ damping corresponding to the maximum scale of each ground motion are presented in Figure 3(A) and (B). To induce relative displacement in a controlled manner and damage the expansion joint specimens sequentially, sine waves were adopted. Damage concentration on one side due to either compressive or tensile deformation was also avoided by the use of sine waves.

There were four limitations to be considered in the test in regard to the period and amplitude of sine wave input. The limitations were: A) shaking table displacement limit, B) shaking table velocity limit, C) SSB displacement limit, and D) SSB static friction force. For each limitation, the inequality regarding the period $T_{g}$ and amplitude $A_{g}$ of the sine wave input, expressed by $\ddot{y}=A_{g} \sin \left(2 \pi / T_{g}\right)$, was derived. 

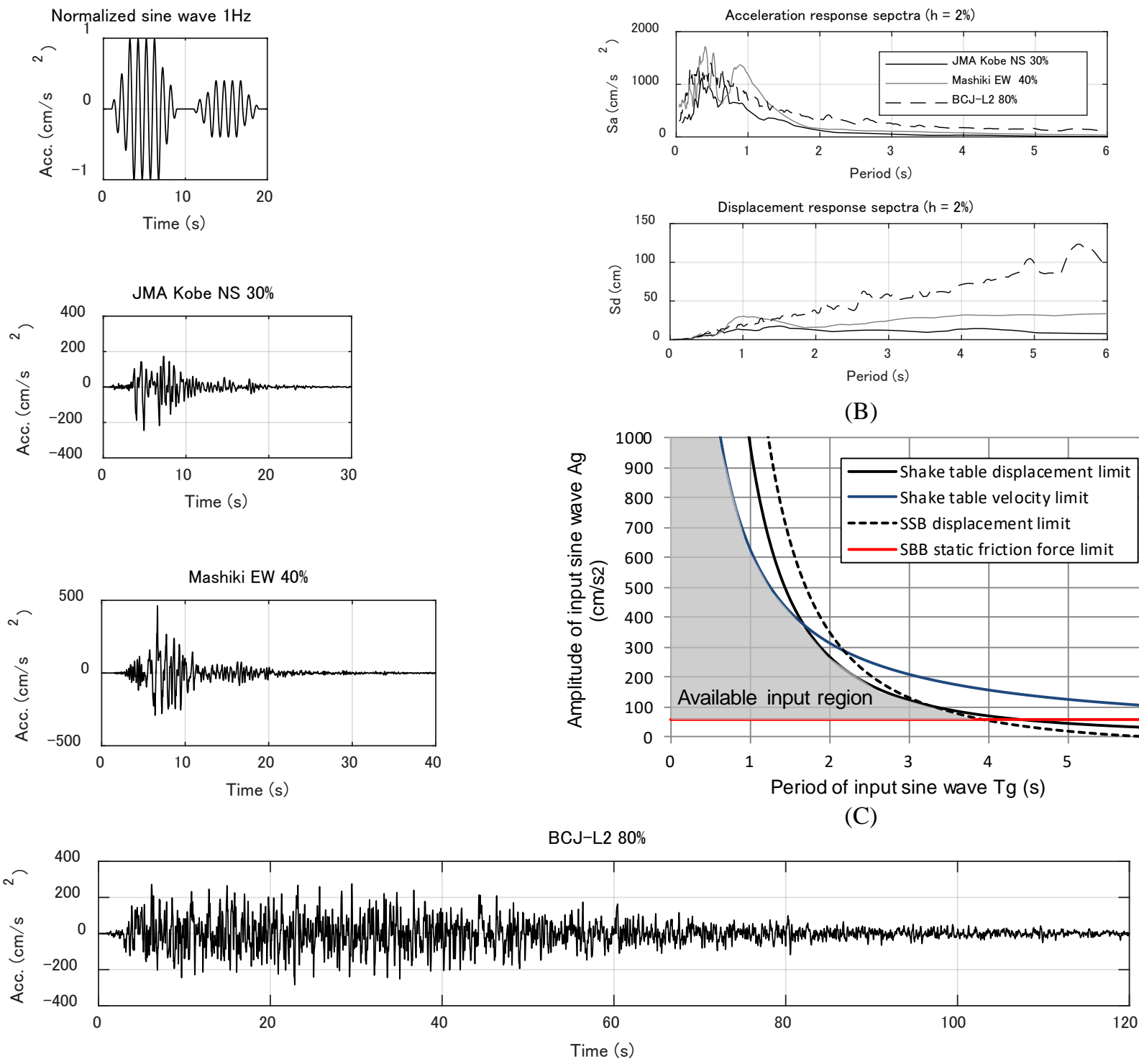

(A)

FIGURE 3 Input waves: (A) time history of input waves, (B) response spectra of input ground motions, and (C) available region of the input sine wave, $\ddot{y}=A_{g} \sin \left(2 \pi / T_{g}\right)$

A) Shaking Table Displacement Limit

The displacement limit of the shaking table was $30 \mathrm{~cm}$. The displacement form of the sine wave is given by

$$
y=-A_{g}\left(\frac{T_{g}}{2 \pi}\right)^{2} \sin \left(2 \pi / T_{g}\right) t
$$

Therefore, the following relation must be satisfied.

$$
A_{g}\left(\frac{T_{g}}{2 \pi}\right)^{2} \leqq 30 \Rightarrow A_{g} \leqq \frac{120 \pi^{2}}{T_{g}{ }^{2}}
$$

B) Shaking Table Velocity Limit

The peak velocity limit of the shaking table for continuous sine waves was $100 \mathrm{~cm} / \mathrm{s}$. The velocity form of the sine wave is as follows:

$$
\dot{y}=-A_{g} \frac{T_{g}}{2 \pi} \cos \left(2 \pi / T_{g}\right) t
$$

Therefore, the following equation must be satisfied.

$$
A_{g} \frac{T_{g}}{2 \pi} \leqq 100 \Rightarrow A_{g} \leqq \frac{200 \pi}{T_{g}}
$$

\section{C) SSB Displacement Limit}


The displacement limit of the SSB was $40 \mathrm{~cm}$. The maximum displacement response of SSB $D_{\max }$ with natural period $T_{S S B}$, subject to sine wave $\ddot{y}=A_{g} \sin \left(2 \pi / T_{g}\right)$, is defined as follows using the deformation response factor $R_{d}$ and damping ratio $h$.

$$
D_{\text {max }}=R_{d} A_{g}\left(\frac{T_{g}}{2 \pi}\right)^{2}
$$

$$
\text { where } R_{d}=\frac{\left(T_{S S B} / T_{g}\right)^{2}}{\sqrt{\left[1-\left(\left(T_{S S B} / T_{g}\right)^{2}\right)^{2}\right]^{2}+\left[2 h\left(T_{S S B} / T_{g}\right)\right]^{2}}}
$$

Therefore, the following equation must be satisfied.

$$
D_{\text {max }}=R_{d} A_{g}\left(\frac{T_{g}}{2 \pi}\right)^{2} \leqq 40 \Rightarrow A_{g} \leqq \frac{160 \pi^{2}}{R_{d} T_{g}{ }^{2}}
$$

\section{D) SSB Static Friction Force}

In the initial state, there is a static friction force $\mu \mathrm{mg}$ between the sliding surface and slider of the SSB, where $\mu$ is the friction coefficient, $m$ is mass, and $g$ is gravity acceleration. Therefore, the amplitude of the sine waves must satisfy the following equation to ensure that slippage occurs.

$$
m A_{g} \geqq \mu m g \Rightarrow A_{g} \geqq \mu g
$$

Substituting the assumed test parameters of the long-period frame, i.e., $\mu=0.0594$ obtained from a proposed equation for SSB [Nishimoto et al 2016], $T_{S S B}=6.0 \mathrm{~s}$, and $h=2.0 \%$, in Equation (2), (4), (6) and (7), the region that satisfies the above inequalities can be obtained as highlighted by the gray color in Figure 3(B).

Within the gray region in Figure $3(\mathrm{~B})$, it is effective to use low-frequency sine waves when a large displacement in the long-period frame is desired. Therefore, it was decided to use a sine wave with $1.0 \mathrm{~Hz}$. A sine wave of $1 \mathrm{~Hz}$ was input with increasing amplitude from $300 \mathrm{~cm} / \mathrm{s}^{2}$ in steps of $50 \mathrm{~cm} / \mathrm{s}^{2}$ until failure of the expansion joints occurred. Figure 3(A) shows the normalized sine wave of $1 \mathrm{~Hz}$ used for the test. The slider of the SSB was accurately re-centered between each input. To investigate the influence of the input frequency on the behavior of the expansion joints, sine waves with $0.5 \mathrm{~Hz}$ and $2.0 \mathrm{~Hz}$ were also inputted within the motion range of the expansion joints.

\section{TESTED SPECIMENS}

\subsection{Overview of expansion joints}

The Japanese Society of Seismic Isolation (JSSI) [JSSI 2013] defines three seismic performance ranks, A, B and C, in expansion joints for base-isolated buildings. The definition of each rank and damage state is described in Tables 1 and 2 . To classify rank A or B of the expansion joints in base-isolated buildings, manufacturers need to conduct a shaking table test to confirm the seismic performance requirements shown in Table 1. Otherwise expansion joints are classified as rank C. Regarding the deformation mechanisms of the expansion joints in base-isolated buildings, four main mechanisms (i.e., slide, lift, expansion and contraction, and others) and dozens of sub-mechanisms (e.g., slide on one side and slide on both sides) can be considered [JSSI 2013]. Any deformation mechanism can be adopted as long as the seismic performance of the expansion joints satisfies the requirements shown in Table 1. This paper mainly refers to the guidelines issued by JSSI, but the Japan Expansion Joints Association, an association consisting of six manufacturers, also issues a guideline that explains the basic behavior and damage states of expansion joints for general buildings [JFJA 2016]. The desirable performance of the expansion joints is explained by referring to the recommendations for aseismic design and the construction of nonstructural components [AIJ 2003].

Although large variations in seismic performance inevitably exist for expansion joints with different deformation mechanisms, seismic performance ranks, and locations in buildings, this study aimed to investigate the representative performance of common types and classify their damage states following the definitions in Table 2. In this context, highperformance (HP) and standard (SD) floor and wall expansion joints were prepared as specimens. The HP expansion joints are for base-isolated buildings and confirmed to rank A through shaking table tests by the manufacturer. These types are custommade. The SD specimens are widely used for typical building structures and their seismic performances were not investigated by shaking table tests. These types were off-the-shelf. The nominal motion range of all specimens in the X-direction was 17.5 $\mathrm{cm}$, which corresponds to $50 \%$ of the clearance of $35 \mathrm{~cm}$. Note that the distance between the two frames was $50 \mathrm{~cm}$ and additional components were attached to the frames in order to achieve the clearance of $35 \mathrm{~cm}$ for the expansion joints. In the following sections, the descriptions (i.e., mechanism and dimensions) of each specimen concern only the X-directional behavior.

TABLE 1 Three performance ranks for expansion joints for base-isolated buildings [JSSI 2013]

\begin{tabular}{|c|c|c|l|}
\hline Rank & Within $5 \mathrm{~cm}$ & Within motion range & Place for use \\
\hline A & Serviceable & Serviceable & $\begin{array}{l}\text { Evacuation routes and places where people } \\
\text { and vehicles often pass }\end{array}$ \\
\hline B & Serviceable & Damage State 1 & Places where people and vehicles pass \\
\hline C & Damage State 1 & Damage State 2 & Places where people rarely pass \\
\hline
\end{tabular}


TABLE 2 Definition of damage state [JSSI 2013]

\begin{tabular}{|l|l|}
\hline Damage State & Descriptions \\
\hline Serviceable & $\begin{array}{l}\text { There are no functional obstacles such as deformation, inclination and clearance. It can be } \\
\text { used after an earthquake without repair. Minor damage such as finish scratches and seal } \\
\text { breaks is acceptable. }\end{array}$ \\
\hline Damage State 1 & $\begin{array}{l}\text { There is no excessive deformation, inclination, or clearance. It is useable by adjustment or } \\
\text { repair after an earthquake. A difference in floor level or a projection in the wall is } \\
\text { observed but not to an extent that hinders passage. }\end{array}$ \\
\hline Damage State 2 & $\begin{array}{l}\text { Large damage occurs but not to the extent of loss of function. It is reusable after large } \\
\text { repair or replacement. A difference in floor level or a projection in the wall is observed, } \\
\text { but falling is not observed. Passing is possible. }\end{array}$ \\
\hline Failure & Its function is lost or it falls down. It is difficult to use after an earthquake. \\
\hline
\end{tabular}

\subsection{HP floor expansion joint}

Figure 4(A)-(D) show the HP floor expansion joint specimen. The expansion joint is certified as A-rank in Table 1 because stable behavior within the motion range has been confirmed by the manufacturer by a shaking table test, but the behavior and damage patterns beyond the motion range were not investigated. The deformation mechanism of this expansion joint is "slide", and the sub-mechanism is "inside slide on one side", as indicated in Figure 4(A). This type was selected because it is commonly used inside buildings where building users pass often. Most of the parts of the expansion joint are made of steel. The deformation in the X-direction is followed by the cylinders described in Figure 4(B) and (D). The cover plate is not fixed in the Z-direction, thus permitting vertical deformation. Expansion joints for base-isolated buildings must hold a central restoring device [JSSI 2013] to avoid a residual displacement, and the bellows-shaped mechanism shown in Figure 4(D) plays this role.

\subsection{HP wall expansion joint}

The HP exterior wall expansion joint specimen is described in Figure 5(A)-(D). The HP expansion joint is also certified as Arank in Table 1. The mechanism of this expansion joint is categorized as "lift" - "lift on one side", and it is made of steel. The cover plate is lifted when the expansion joint is subjected to displacement in the Y-direction or compressive displacement in the X-direction, but the springs function to return the cover plate to the original position after excitation. This expansion joint was made by the same expansion joint manufacturer as the HP floor expansion joint. In the test setup, one HP wall expansion joint specimen was set between two frames at the front side, with the HP floor expansion joint specimen installed above.

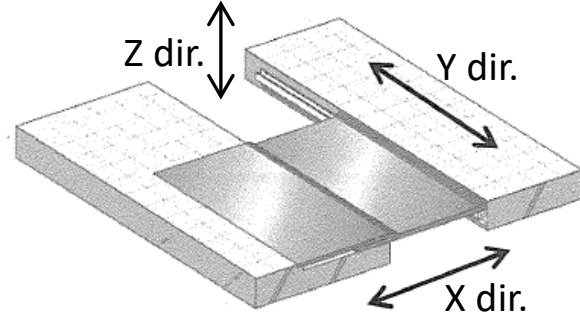

(A)

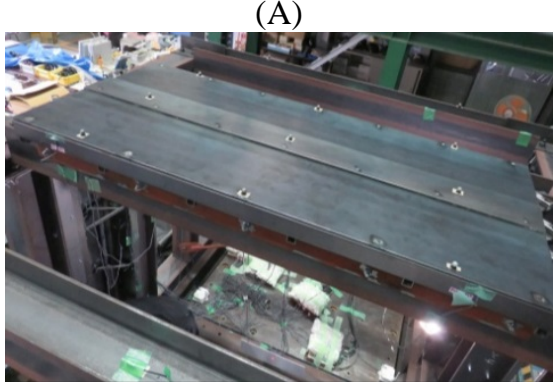

(C)

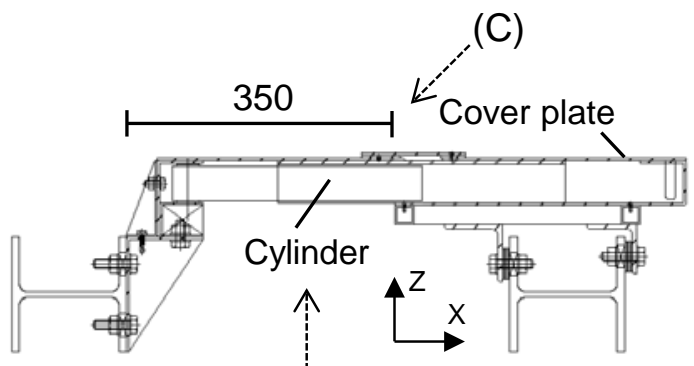

(D)

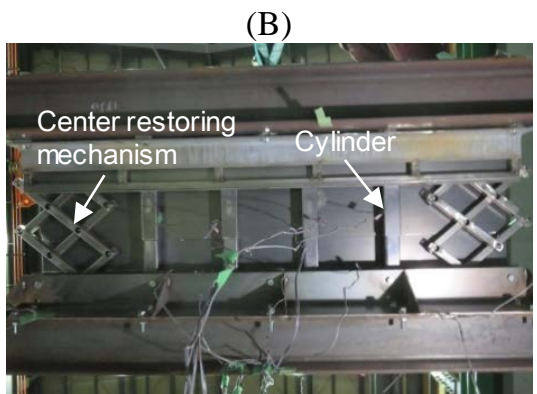

(D)

FIGURE 4 HP floor expansion joint specimen (unit: mm): (A) deformation mechanism [JSSI 2013], (B) drawing, (C) top view, and (D) bottom view 

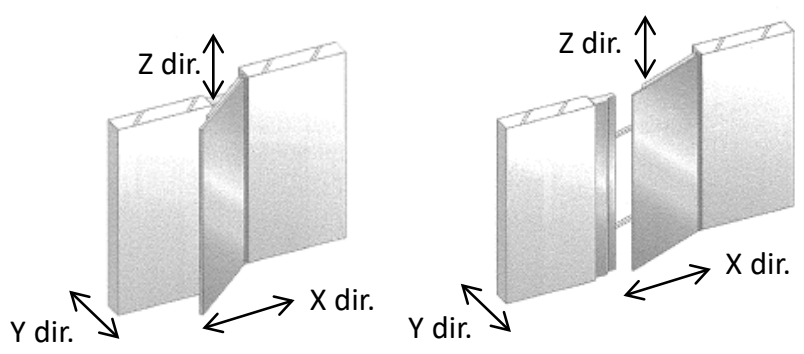

(A)

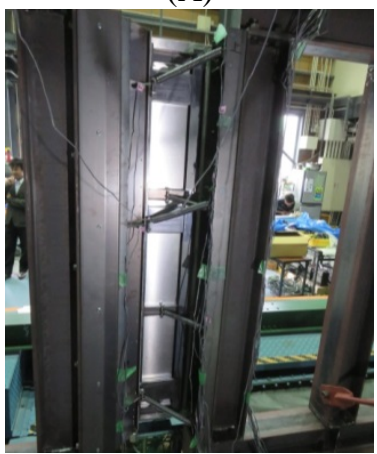

(C)

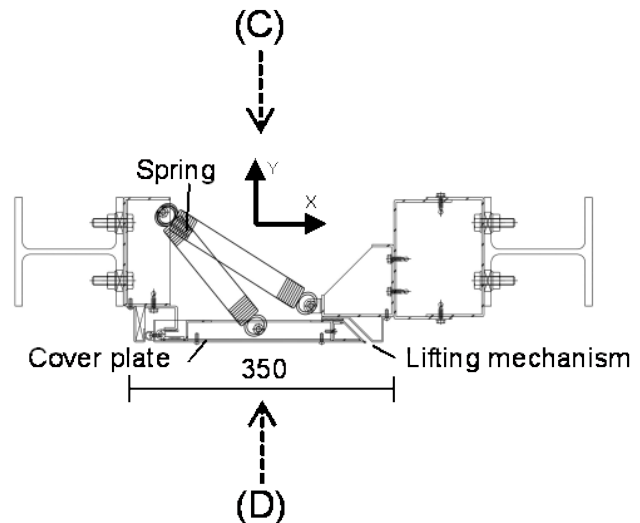

(B)

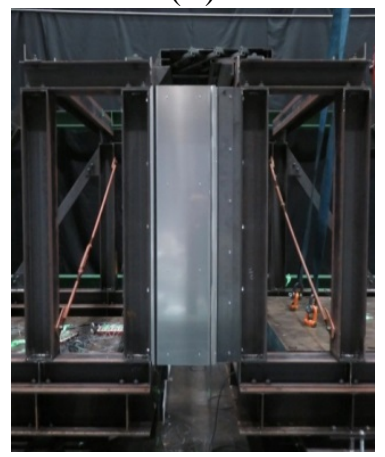

(D)

FIGURE 5 HP wall expansion joint specimen (unit: mm): (A) deformation mechanism [JSSI 2013], (B) drawing, (C) inside view, and (D) front view

\subsection{SD floor expansion joint}

The SD floor expansion joint specimen is described in Figure 6(A)-(D). The type of its mechanism is classified as "slide""inside slide on both sides". Because of its simplicity, this joint is widely used in large-scale buildings such as commercial buildings, office buildings, and apartment houses. This expansion joint is not for base-isolated buildings and therefore cannot be classified as A- or B- or C-rank in Table 1 because those ranks are intended for base-isolated buildings. It is composed of an unfixed center cover plate with side plates made of stainless steel. Rubber sheets are fixed in between the cover plate and side plates to ensure that the cover plate does not move easily simply due to people passing over it. There are a total of twenty drill screws (M4) at the side plates. In contrast to the HP floor expansion joint, this expansion joint exhibits a residual displacement after an excitation because there is no center-restoring mechanism.

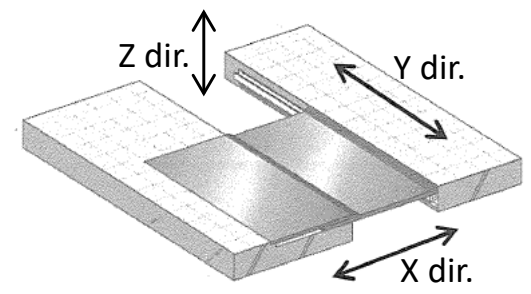

(A)

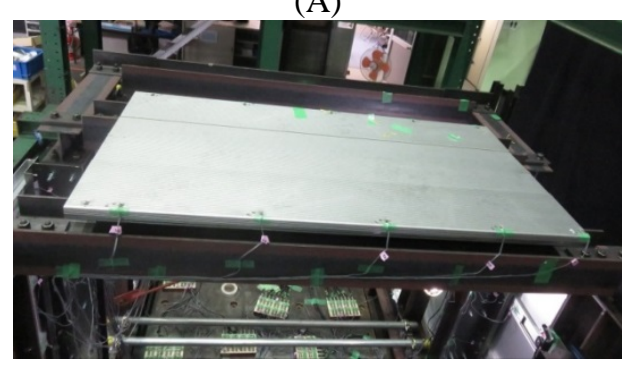

(C)

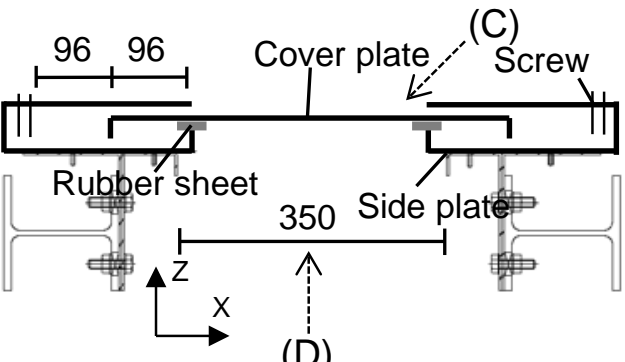

(B)

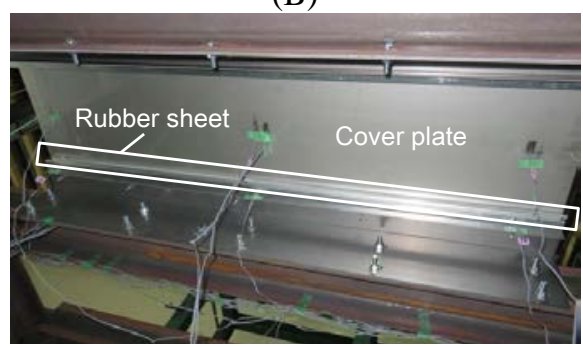

(D)

FIGURE 6 SD wall expansion joint specimen (unit: mm): (A) deformation mechanism [JSSI 2013], (B) drawing, (C) top view, and (D) bottom view 


\subsection{SD wall expansion joint}

Figure 7 displays the SD exterior wall expansion joint specimen. The mechanism is categorized as "slide" - "rail slide". This expansion joint is also not for isolated buildings and cannot be classified according to the ranks in Table 1 . The cover plate is equipped with four sliders that permit deformation in the X-direction. The length of the slider is $17.5 \mathrm{~cm}$. Therefore, it is expected that, after the relative displacement of $17.5 \mathrm{~cm}$ is applied, the sliders will be removed from the sliding path, and the cover plate will fall. All plates and sliders are made of aluminum. In the experiment, as in practice, falling of the cover plate was prevented by a safety rope. Together with the SD floor expansion joint, two SD wall expansion joints were set between the two frames at both the front and back sides.

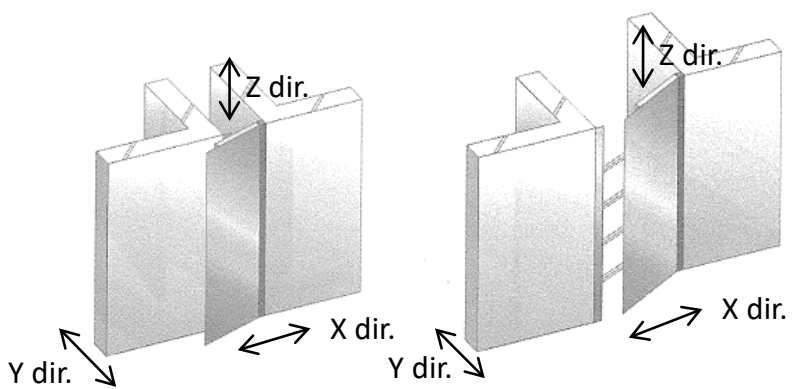

(A)

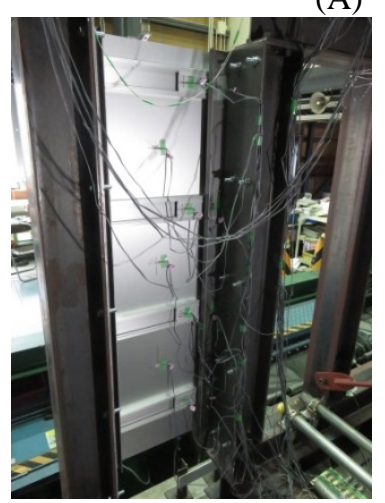

(C)

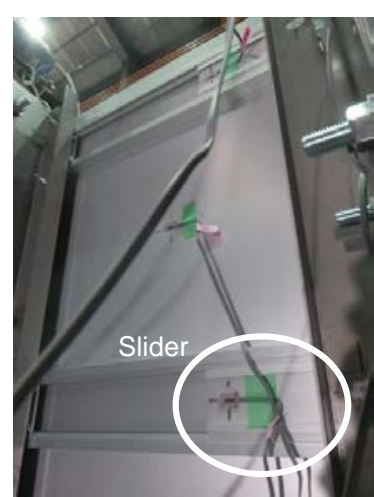

(D)

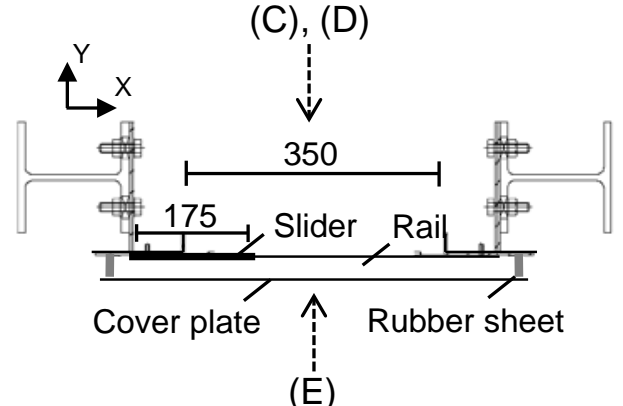

(B)

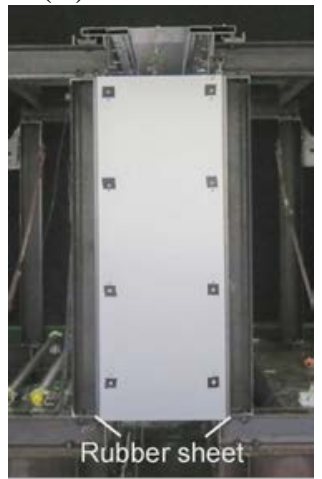

(E)

FIGURE 7 SD wall expansion joint specimen (unit: mm): (A) deformation mechanism [JSSI 2013], (B) drawing, (C) inside view, (D) slider, and (E) front view

\section{TEST RESULTS}

\subsection{Overall behavior}

Before reporting damage to the expansion joints, this section investigates whether the two steel frames and expansion joints exhibited the dynamic behavior as designed. Figure 8 shows the hysteresis loops and displacements of the two steel frames for a 30\%-scale acceleration record in the EW direction at Mashiki Town recorded in the 2016 Kumamoto earthquake. The gray and black solid lines correspond to the displacement of the short- and long-period frames, respectively. In the hysteresis loops, the short-period frame exhibited elastic behavior, and its displacement was less than $5 \mathrm{~cm}$. The long-period frame slid with low secondary stiffness after overcoming the static friction force, and its maximum displacement reached nearly $10 \mathrm{~cm}$. The relationship between the relative displacement, depicted by the red line, and the displacement of each frame was examined. In the relative displacement, the long-period pulse was mainly generated by the sliding of the long-period frame, and the shortperiod motions were mainly generated by the vibration of the short-period frame. This tendency was also observed during the inputs of a sine wave of $1 \mathrm{~Hz}$. Both the HP and SD expansion joint specimens showed stable behaviors as designed, and no damage was observed within the design motion range. Note that the long-period frame exhibited some rotational movement as the displacement at the front and back side differed by approximately $1 \mathrm{~cm}$. Thus, the average of the values of the front and back sides is presented here.

Figure 9 presents the relationship between the peak acceleration response at the short-period frame and the peak relative displacement between the two frames. Each plot corresponds to each input and red plot corresponds to the damage cases described later. It is observed that there is almost no damage within the motion range of the expansion joints regardless of type of inputs such as the ground motions and sine waves with $0.5 \mathrm{~Hz}, 1.0 \mathrm{~Hz}$, and $2.0 \mathrm{~Hz}$. These results indicate that the expansion joints exhibited stable and identical behavior within the motion range regardless of input waves. With respect to the behavior or damage of the expansion joints beyond the motion range, some differences can be expected depending on the type of inputs or building characteristics. For example, a collision between the components of the expansion joints at a low frequency or 
repeated collisions at a high frequency may cause a difference in damage patterns of the expansion joints. However, such behavior was not investigated in this paper.

The dependency of the damage to the expansion joints on the peak relative displacement or acceleration response is discussed. Figure 9 demonstrates that the sine waves of $2.0 \mathrm{~Hz}$ frequency and the ground motions caused a large acceleration response within the motion range of expansion joints, but there was no damage to them. In contrast, when the peak relative displacement exceeded the motion range, several damage patterns were observed. These results indicate that damage to the expansion joints was affected more by the peak relative displacement than the peak acceleration. Note that significantly large accelerations were observed at the damage cases especially for the HP expansion joints. These peak accelerations occurred when collisions between the components of the expansion joints occurred. Thus, the large acceleration was not the cause, but the result of the damage to the expansion joints. This point will be described in detail at a later section.

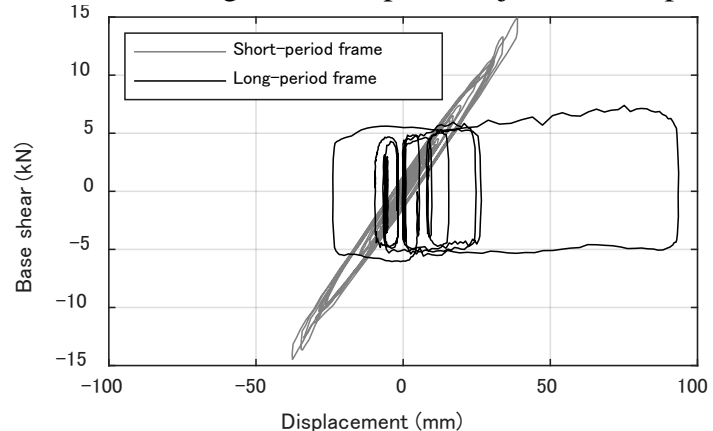

(A)

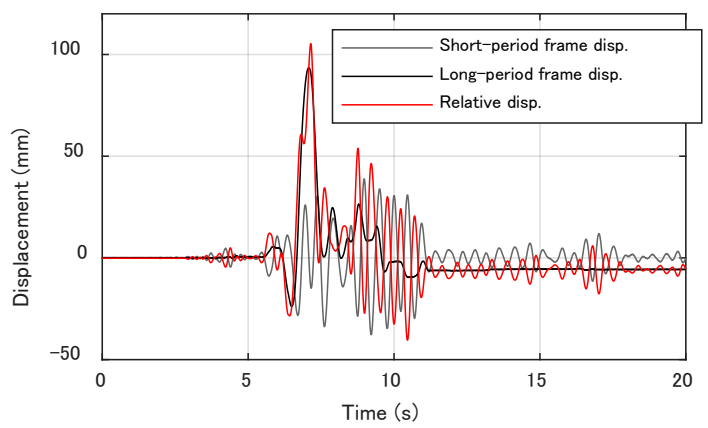

(B)

FIGURE 8 Dynamic behavior of the two frames: (A) hysteresis loops and (B) displacements

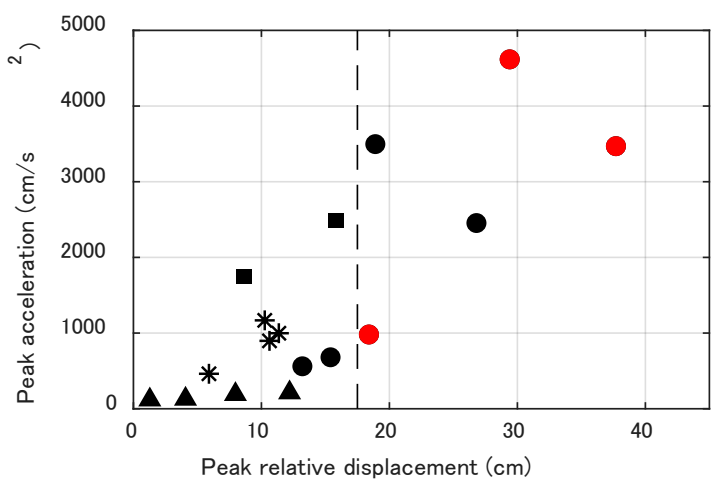

(A)

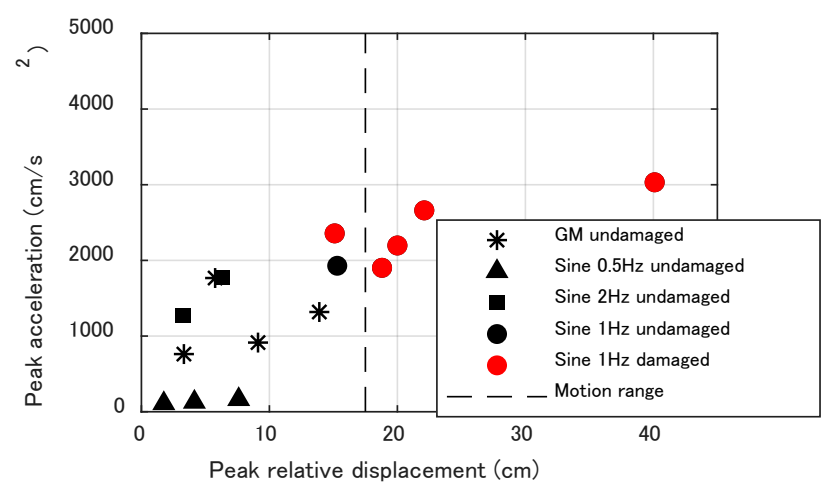

(B)

FIGURE 9 Peak relative displacement vs peak acceleration response at the short-period frame for each input: (A) HP expansion joints and (B) SD expansion joints

\subsection{Force applied to expansion joint specimens}

\subsubsection{Equation for force evaluation}

This section explores the amplitudes of the force applied to the expansion joint specimens and the relationship between the timing of the large force input and damage occurrence. The procedure for estimating the force applied to the expansion joint specimens followed the computing method used for seismic pounding problems between adjacent buildings [Anagnostopoulos 1988]. Equation (8) describes the equation of motion for a system without expansion joints under an input of $\ddot{y}$, whereas Equation (9) expresses the equation of motion for a system with expansion joints. The only differences are the response of acceleration $\ddot{x}$, displacement $x$, and the force applied to the expansion joints $F_{\text {exp } j}$. Note that the damping force is neglected in the motion of equation because it is expected that the tested frames had a small damping ratio. In addition, mass $m$ and stiffness $k$ are considered equal between systems with and without expansion joints because these values are small for the expansion joints.

$$
\begin{gathered}
m \ddot{x}_{w o}+k x_{w o}=-m \ddot{y} \\
m \ddot{x}_{w}+k x_{w}+F_{\text {expj }}=-m \ddot{y}
\end{gathered}
$$

Using Equations (8) and (9), Equation (10) can be derived.

$$
F_{\text {expj }}=m\left(\ddot{x}_{w o}-\ddot{x}_{w}\right)+k\left(x_{w o}-x_{w}\right)
$$

Consequently, $F_{\text {expj }}$ is obtained by comparing the mass, stiffness, displacement response, and acceleration response of systems with and without expansion joints under the same input. 


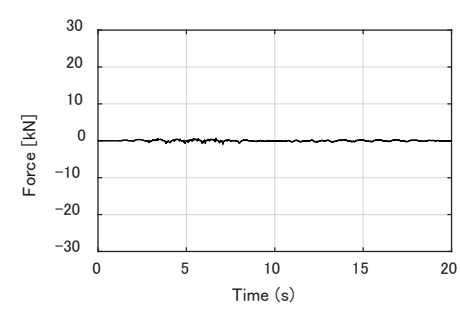

(A)

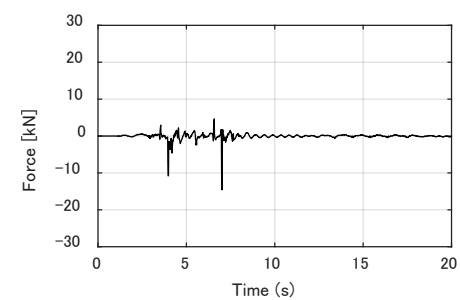

(D)

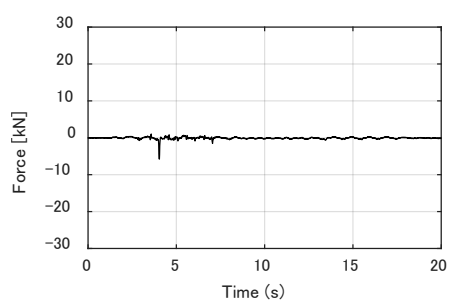

Wall: $1 / 5$ springs deformed

(B)

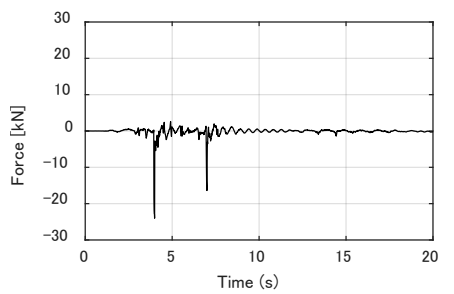

Wall: 1/6 screws ruptured

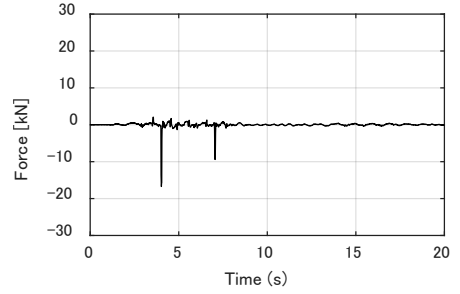

(C)

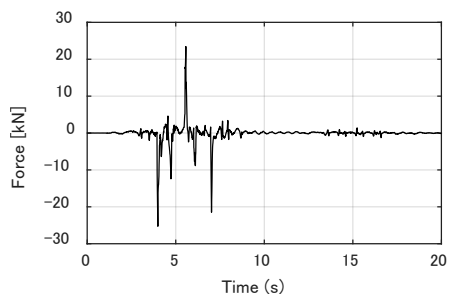

Floor: Cover plate disengaged

Wall: 6/6 screws ruptured, 3/5 springs deformed

(F)

FIGURE 10 Force applied to HP expansion joints with damage descriptions: (A) $350 \mathrm{~cm} / \mathrm{s}^{2}$, (B) $400 \mathrm{~cm} / \mathrm{s}^{2}$, (C) $450 \mathrm{~cm} / \mathrm{s}^{2}$, (D) $500 \mathrm{~cm} / \mathrm{s}^{2}$, (E) $550 \mathrm{~cm} / \mathrm{s}^{2}$, and (F) $600 \mathrm{~cm} / \mathrm{s}^{2}$

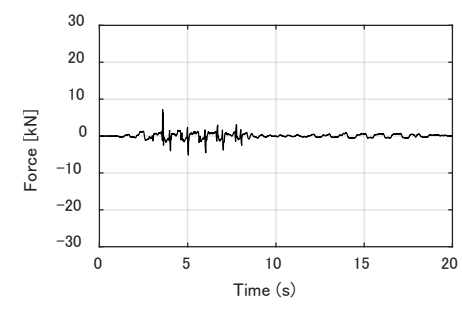

(A)

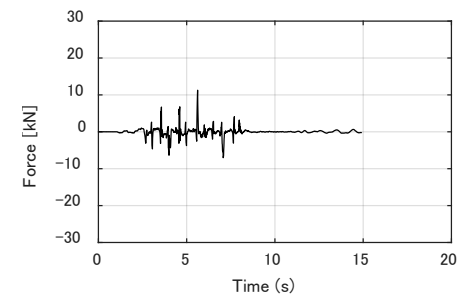

Floor 9/20 screws ruptured Wall (back): Cover plate dropped off

(D)

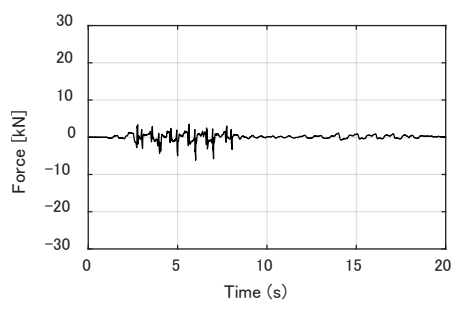

Wall: Rubber sheet disengaged

(B)

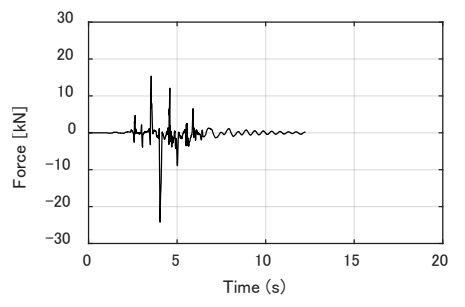

Floor: Cover plate disengaged

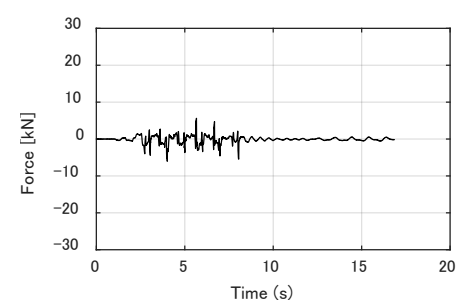

Floor: 5/20 screws ruptured Wall (front): Cover plate dropped off

(C)

FIGURE 11 Transition of force applied to SD expansion joints with damage descriptions: (A) $350 \mathrm{~cm} / \mathrm{s}^{2}$, (B) $400 \mathrm{~cm} / \mathrm{s}^{2}$, (C) $450 \mathrm{~cm} / \mathrm{s}^{2}$, (D) $500 \mathrm{~cm} / \mathrm{s}^{2}$, and (E) $550 \mathrm{~cm} / \mathrm{s}^{2}$

Theoretically, $F_{\text {expj }}$ can be derived from whichever response of the short-period frame and long-period frame by using Equation (10), but the short-period frame was used here because the force-displacement relationship of the short-period frame was elastic. Hence, $\ddot{x}_{w}$ and $x_{w}$ were acquired from the responses of the short-period frame. To obtain $\ddot{x}_{w o}$ and $x_{w o}$, another test was conducted for the short-period frame without expansion joints under the same loading protocol used for the test of the expansion joint specimens. The mass $m$ of the short-period frame was $20.6 \mathrm{kN}$, and the stiffness $k$ was identified as $3.92 \mathrm{kN} / \mathrm{cm}$ from the acceleration response of the short-period frame without expansion joints.

\subsubsection{Force applied to HP expansion joints}

The force $F_{\text {expj }}$ applied to the HP expansion joint specimens was derived from the above procedures. Figure 10 shows the time history of $F_{\text {expj }}$ with damage descriptions for the specimen subject to different amplitudes of sine wave $1.0 \mathrm{~Hz}$. The negative value indicates that a force was applied when the two frames approached. Note that $F_{\text {expj }}$ is the total force applied to the floor and wall expansion joint specimens. At first, during the input of the $350 \mathrm{~cm} / \mathrm{s}^{2}$ excitation, no force was observed on the expansion joints, which validated the smooth movement of the expansion joint specimen. Under $400 \mathrm{~cm} / \mathrm{s}^{2}$, damage occurred at one of the five springs of the HP wall expansion joint specimen. This could be related to the peak force in the negative side. From $450 \mathrm{~cm} / \mathrm{s}^{2}$ and beyond, the two steel frames collided repeatedly, and the resulting force increased as the input amplitude increased. Under $550 \mathrm{~cm} / \mathrm{s}^{2}$, approximately $-25 \mathrm{kN}$ was observed at the first collision, which resulted in the fracture of one of 
the six screws. After $600 \mathrm{~cm} / \mathrm{s}^{2}$, all six screws and two other springs at the HP wall expansion joint specimen were broken. The cover plate of the HP floor expansion joint specimen was also disengaged when the two frames moved away from each other.

\subsection{3. $\quad$ Force applied to SD expansion joints}

Figure 11 illustrates the time history of $F_{\text {expj }}$ for the SD floor and wall expansion joints with damage descriptions. In general, $F_{\text {expj }}$ was smaller for the SD specimens than for the HP specimens because the two frames connected with the SD expansion joint specimens did not experience a collision. Several peaks of small forces were observed due to collisions between the cover plate and the screws of the SD floor expansion joint specimens. Even though the cover plate of the SD wall expansion joint specimens fell off under the $450 \mathrm{~cm} / \mathrm{s}^{2}$ and $500 \mathrm{~cm} / \mathrm{s}^{2}$ excitations, a large force did not appear. This was because the sliders of the SD wall expansion joint specimens railed off smoothly. Under $550 \mathrm{~cm} / \mathrm{s}^{2}$, the large negative force was observed because the cover plate of the SD floor expansion joint specimen collided with the side plates. The large positive force appeared when the cover plate of the SD floor expansion joint was disengaged.

\section{DAMAGE STATE CLASSIFICATION OF EXPANSION JOINTS}

\subsection{Overview}

This section aims to classify the damage states of the tested expansion joints. Table 3 summarizes the damage states observed in the tests. Damage state 1 (DS1) and failure are sequential damage, and DS-1A and DS-1B are simultaneous damage states [Porter et al 2007]. Most of the damage patterns can be categorized as displacement sensitive, and therefore the measured relative displacement at the time of damage with respect to the design motion range of $17.5 \mathrm{~cm}$ is presented. The relative displacements for the floor expansion joint specimens were obtained by the D9 sensor, and those for the wall expansion joint specimens were obtained by D2 and D6 for the front side and D1 and D5 for the back side. The positive values of relative displacement correspond to the situation in which the two frames move away from each other, which is called the tension side, and the negative values are called the compression side.

TABLE 3 Summary of the observed damage states through the shake table testing

\begin{tabular}{|l|l|l|}
\hline Specimen & Damage State & $\begin{array}{l}\text { Relative displacement at the moment of damage } \\
\text { (ratio to the design motion range of 17.5 } \mathrm{cm})\end{array}$ \\
\hline HP Floor & DS1: cover plate disengaged & $33.8 \mathrm{~cm}(193 \%)$ \\
\hline \multirow{2}{*}{ HP Wall } & DS1-A: spring deformation & $\begin{array}{l}19.1 \mathrm{~cm} \text { for one spring and } 23.6 \mathrm{~cm} \text { for the other } \\
\text { two springs }(109 \% \text { and } 132 \%)\end{array}$ \\
\cline { 2 - 3 } & DS1-B: screw rupture & $20.3 \mathrm{~cm}(116 \%)$ \\
\hline \multirow{2}{*}{ SD Floor } & DS1: screw rupture & $9.4 \mathrm{~cm}(54 \%)$ \\
\cline { 2 - 3 } & Failure: cover plate disengaged & $22.2 \mathrm{~cm}(127 \%)$ \\
\cline { 2 - 3 } & DS1: rubber sheet disengaged & $-($ Due to rubbing with other components) \\
\cline { 2 - 3 } & Failure: cover plate dropped off & $\begin{array}{l}17.6 \mathrm{~cm} \text { for the front side and } 19.0 \mathrm{~cm} \text { for the back } \\
\text { side (101\% and 109\%) }\end{array}$ \\
\hline
\end{tabular}

\subsection{Damage states of HP expansion joints}

\subsubsection{HP floor expansion joint "DS1: cover plate disengaged"}

The first damage pattern observed for the HP floor expansion joint was cover plate disengagement during the input of 600 $\mathrm{cm} / \mathrm{s}^{2}$, as shown in Figure 12(A)-(B). Figure 12(C) shows the relative displacement corresponding to each condition described in Figure 12(D). Based on Figure 12(D) and videos, the relative displacement in the tension side immediately before the collision, noted as (2), was $33.8 \mathrm{~cm}$. At this deformation, the plate underneath the cover plate could no longer support the cover plate. As a result, the cover plate was inclined to the inner side, and the collision (3) occurred. After the collision (3), the cover plate was dislocated from the holes, noted as (4), and freely stood (5). Then, the two frames approached the relative displacement of $23.0 \mathrm{~cm}$, and the collision (6) occurred. Finally, the cover plate fell off and disrupted the displacement sensor D9 (7). This damage was induced by the two collisions at (3) and (6) in Figure 12(D), and these collisions caused the large peak accelerations in Figure 9 as mentioned before. The second collision did not occur without the first collision, but there is also a possibility that the cover plate fell off due to the first collision. Therefore, the first collision was considered critical, and the critical relative displacement of this damage was evaluated as $33.8 \mathrm{~cm}$ in the tension side. This value is $193 \%$ of the design motion range of $17.5 \mathrm{~cm}$, and thus the tested HP expansion joint has a sufficient safety margin beyond the design tolerance.

This expansion joint can be reused immediately after re-engaging the cover plate according to the expansion joint manufacturer. Therefore, following the definition in Table 2, this damage was defined as damage state 1. Even though this was not a failure state, loadings were finished because the displacement response of the SSBs nearly reached the maximum capacity of $40 \mathrm{~cm}$. 


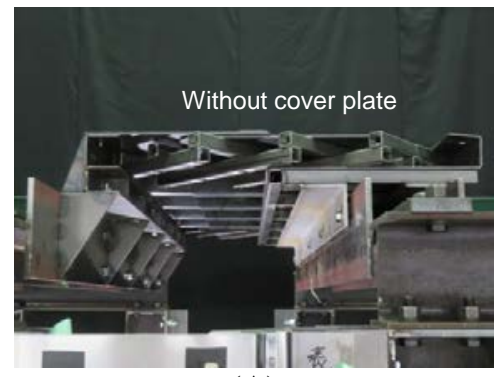

(A)

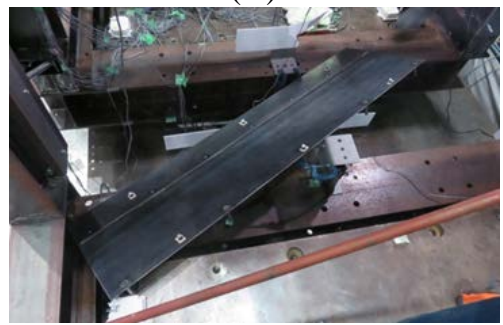

(B)

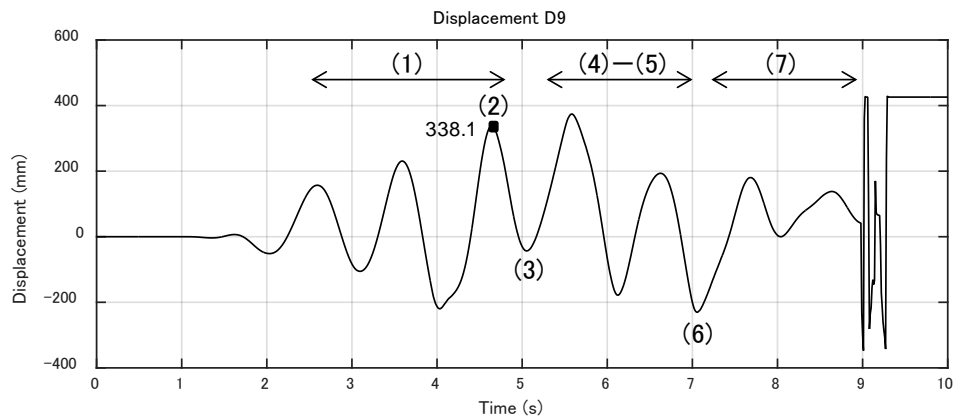

(C)

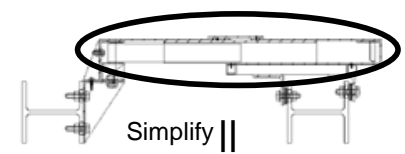

Unfixed in vertical direction

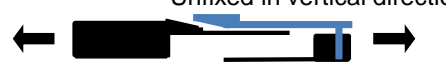

(2)

(3)

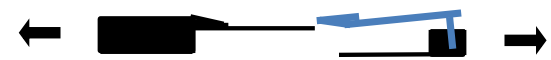

(4)

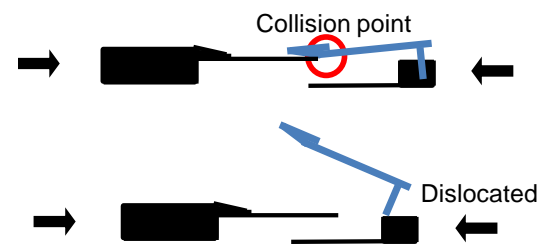

(5)

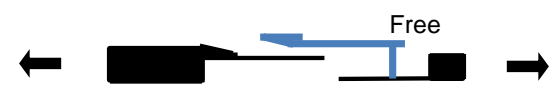

(6)

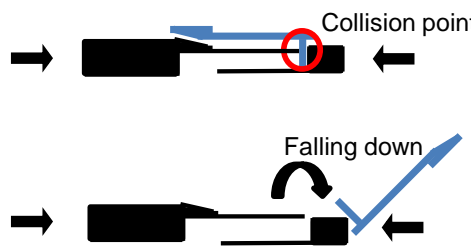

(D)

FIGURE 12 HP floor specimen DS1 (cover plate disengaged): (A) after cover plate disengagement, (B) dropped cover plate, $(C)$ relative displacement during input of $600 \mathrm{~cm} / \mathrm{s}^{2}$, and (D) descriptions of damage sequence

\subsubsection{HP wall expansion joint "DS1-A: spring deformation"}

There were five springs (three of spring A and two of spring B in Figure 13(A) inside the HP wall expansion joint specimen. Their function was to pull back the cover plate from rotation. Excited by the sine wave of $400 \mathrm{~cm} / \mathrm{s}^{2}$, one spring A at the top was caught on a surrounding member at the time of compression, and a residual deformation remained in the spring. This was confirmed by video. Because there was no residual rotation at the cover plate, this damage was classified as damage state 1.

After the input of $600 \mathrm{~cm} / \mathrm{s}^{2}$, two spring B sustained residual deformation. Figure 13(C) shows the time history response of the strain gauge labeled W9 attached close to the base material and the relative displacement between two frames. There were two peaks in the response of strain W9, which were attributed to a collision with springs or other materials. The relative displacements at the timing of the strain peaks were $17.9 \mathrm{~cm}$ and $23.2 \mathrm{~cm}$ in the compression side. Therefore, this damage depended on the relative displacement in the compression side. The critical relative displacement of this damage was evaluated as the maximum relative displacement in the compression side, which was $23.2 \mathrm{~cm}$ for the input of $600 \mathrm{~cm} / \mathrm{s}^{2}$ and $19.1 \mathrm{~cm}$ for $400 \mathrm{~cm} / \mathrm{s}^{2}$. These values are beyond the design motion range, and the seismic performance of this expansion joint satisfied the required performance in Table 1.

\subsubsection{HP wall expansion joint "DS1-B: screw rupture"}

Another damage state observed for the HP wall expansion joint was the rupture of screws at the base materials as shown in Figure 14(A) and (B). The damaged screws were M6 drill screws. At the input of a sine wave of $550 \mathrm{~cm} / \mathrm{s}^{2}$, the base materials collided twice at the collision point indicated in Figure 14(B), and one of the six screws fractured. Under the input of $600 \mathrm{~cm} / \mathrm{s}^{2}$, the other five screws were also fractured. Even without screws, this expansion joint retained its function, and a small repair was required. Thus, this damage was defined as damaged state 1. Because "DS-1A: spring deformation" occurred at the same time, these damage states were classified as simultaneous damage.

Figure 14(C) shows the response of the strain gauge W3 attached next to the collision point and the response of the relative displacement against the input of $600 \mathrm{~cm} / \mathrm{s}^{2}$. From the peak points in the strain response, the exact moments of the collisions and the corresponding relative displacements were identified. According to Figure 14(C), the first collision occurred at a relative displacement of $20.3 \mathrm{~cm}$, which was $0.7 \mathrm{~cm}$ smaller than the collision length described in Figure 14(B), with little 
construction errors. All screws were nearly fractured at the first collision, and thus a larger relative displacement of $22.4 \mathrm{~cm}$ was required at the second collision because the surrounding materials moved due to the loss of the screws.

Based on the above analysis, this damage state clearly depends on the relative displacement and the collision length. In summary, two patterns of damage state 1 were observed when the relative displacement was nearly equal to 110 and $130 \%$ of the design motion range. Although the experiment ended without observing the failure state, the margin of failure should be larger than $130 \%$ of the design motion range.

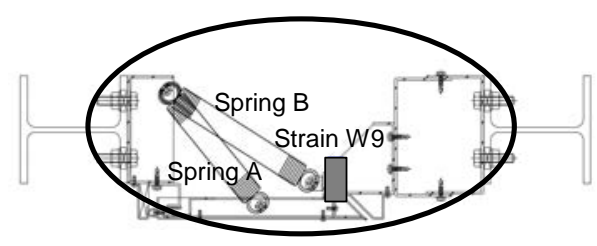

Simplify ||

(1)

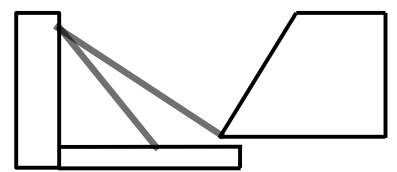

(2)

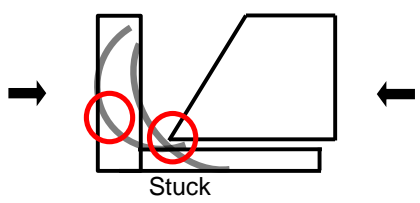

(3)

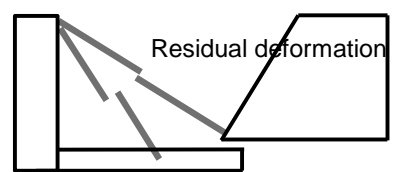

(A)

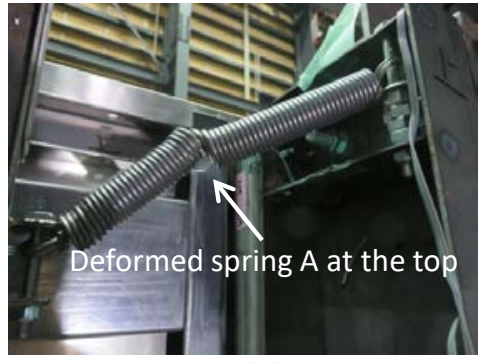

(B)

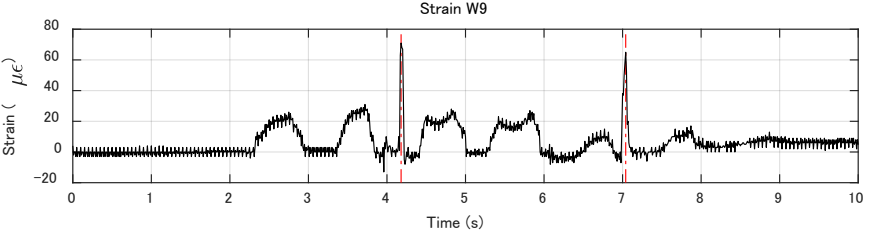

Displacement D2-D

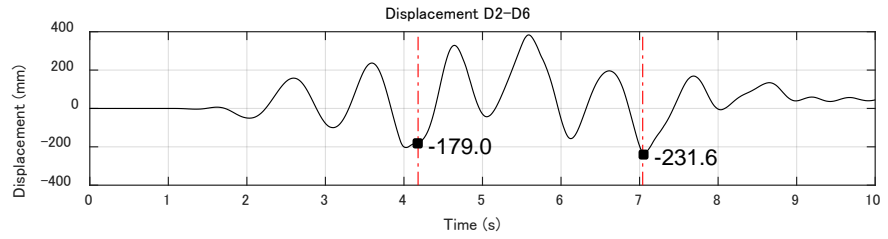

(C)

FIGURE 13 HP wall specimen DS1-A (spring deformation): (A) damage sequence, (B) residual deformation of spring $A$ after input of $400 \mathrm{~cm} / \mathrm{s}^{2}$, and (C) strain and relative displacement response during $600 \mathrm{~cm} / \mathrm{s}^{2}$

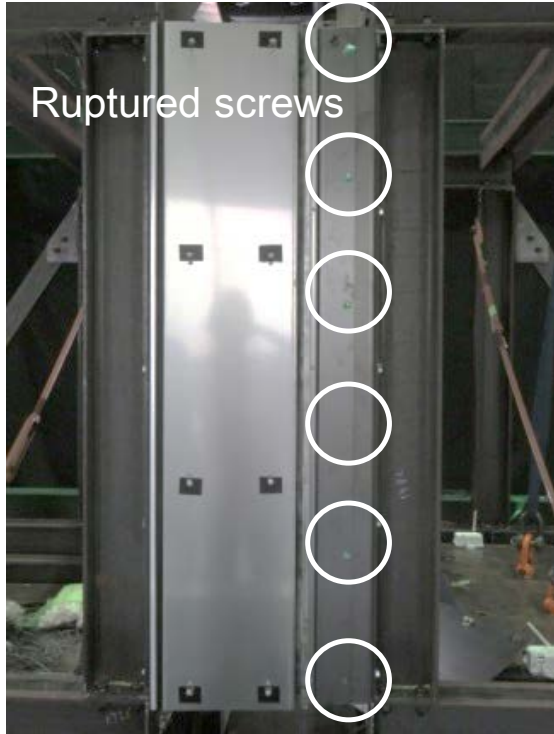

(A)

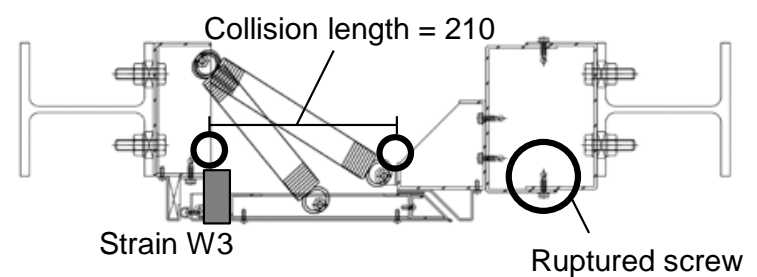

(B)
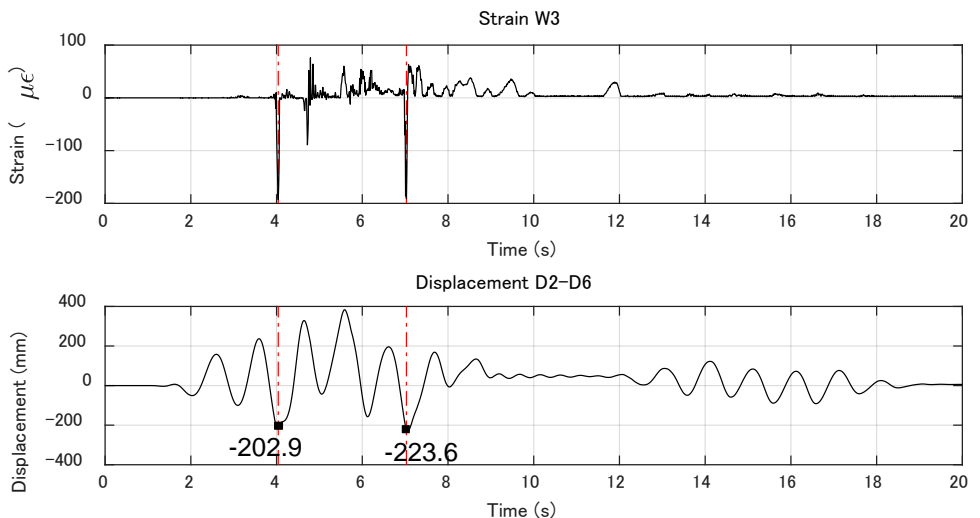

(C)

FIGURE 14 HP wall specimen DS1-B (screw rupture) (unit: mm): (A) damage location; (B) damage descriptions in the drawing, and $(C)$ strain and relative displacement during the excitation under $600 \mathrm{~cm} / \mathrm{s}^{2}$ 


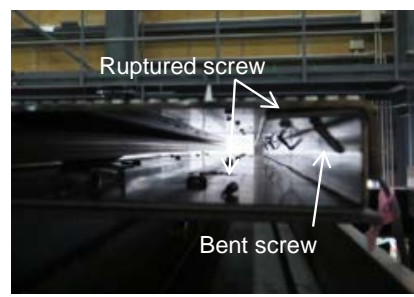

(A)

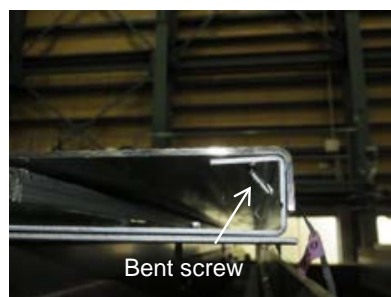

(B)

(1)

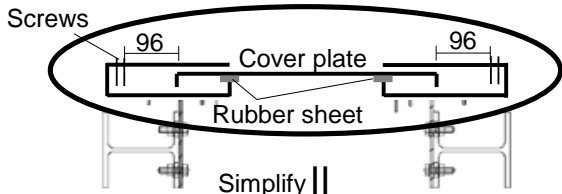

Strain F7

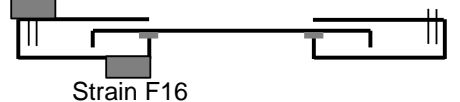

(2)

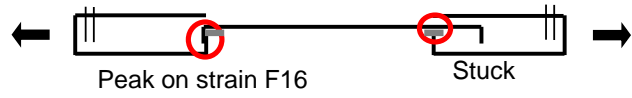

(3)

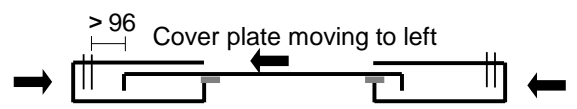

(5)

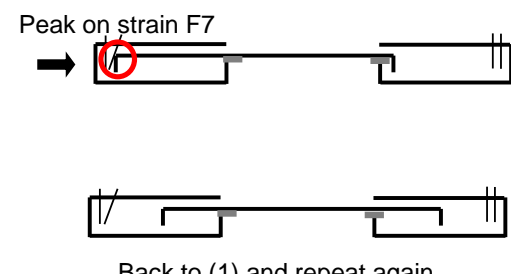

Back to (1) and repeat again

(D)

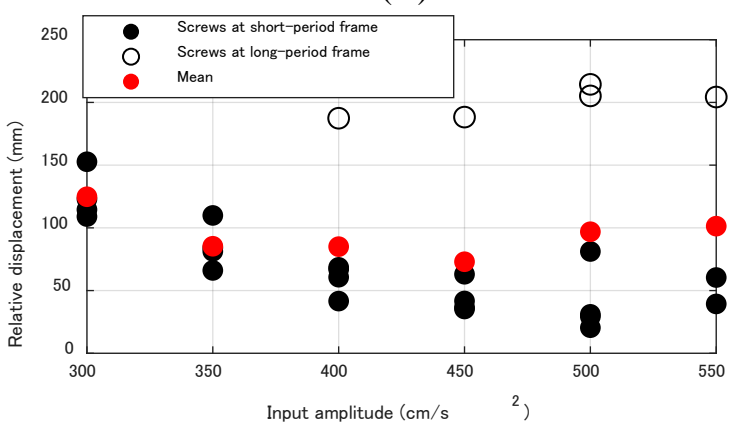

(F)

FIGURE 15 SD floor specimen DS1 (screw rupture) (unit: $\mathrm{mm}$ ): (A) bending and fracture of screws, (B) bent screw, (C) strain and relative displacement during the input of $450 \mathrm{~cm} / \mathrm{s}^{2}$, (D) damage sequence, (E) disengagement of rubber sheets, and (F) relative displacement at the moment of collision for each input

\subsection{Damage states of SD expansion joints}

\subsubsection{SD floor expansion joint "DS1: screw rupture"}

In the SD floor expansion joint specimen, the first observed damage was the fracture of several drill screws, as shown in Figure 15(A)-(B). In the design drawing in Figure 15(D), the distance between the edge of the cover plate and the screws is $9.6 \mathrm{~cm}$. Under the input of $300 \mathrm{~cm} / \mathrm{s}^{2}$ or larger, the cover plate hit the screws, resulting in bending and fracture of the screws. Under the input of $450 \mathrm{~cm} / \mathrm{s}^{2}$, five of twenty screws were shear fractured. Four more screws were shear fractured under the input of 500 $\mathrm{cm} / \mathrm{s}^{2}$. Damaged screws can be easily replaced from above the cover plate and thus this damage was considered damage state 1.

The sequence of the damage during the input of $450 \mathrm{~cm} / \mathrm{s}^{2}$ is described in Figure 15(D). Ideally, a collision between the cover plate and screws should occur at a relative displacement of $9.6 \times 2=19.2 \mathrm{~cm}$. However, in the experiment, the cover plate moved toward one side due to the imbalanced friction force between the cover plate and the two rubber sheets, and the collision occurred at less than $19.2 \mathrm{~cm}$. For example, under the $450 \mathrm{~cm} / \mathrm{s}^{2}$, the cover plate collided with the screws on the shortperiod frame side only. The collisions at (2) in Figure 15(D) represent peaks at strain gauge F16 in Figure 15(C). Assuming that the timing of the collisions at (4) in Figure 15(D) correspond to peaks at strain gauge F7 attached close to the screws, there were four collisions (double-checked by videos). From Figure 15(C), the relative displacements at the moment of these collisions were measured as $4.2 \mathrm{~cm}, 6.3 \mathrm{~cm}, 3.7 \mathrm{~cm}$ and $3.5 \mathrm{~cm}$ in the compression side. Due to the repetition of those collisions, the screws ultimately fractured. After repeated loadings, the rubber sheet was also disengaged as shown in Figure 15(E), and the friction force between the cover plate and rubber sheet differed between the short-period and long-period frame sides. 
The relative displacement at which the collision occurred was different for each input. Figure 15(F) shows the relative displacement at the collisions for each input. The black circle indicates the collision of the cover plate and screws on the shortperiod frame side, whereas the open circle indicates the collision on the long-period frame side. The red circle indicates the average relative displacement for each input. As the input progressed, the collision on the short-period frame side occurred with smaller displacements because the friction force between the cover plate and rubber sheet differed for the short-period and long-period frame sides. The average relative displacement for each input, represented by the red circle, was uniformly distributed between $8 \mathrm{~cm}$ to $12 \mathrm{~cm}$. The mean value of all points was calculated as $9.44 \mathrm{~cm}$, which equals nearly one half of the expected collision distance of $19.2 \mathrm{~cm}$ based on the drawing. In summary, while there were influences of repeated loading, collisions occurred at one-half of the expected length in the design drawing due to the variance in the friction coefficient between the rubber sheets and cover plate.

\subsubsection{SD floor expansion joint "Failure: cover plate disengaged"}

Figure 16(A)-(B) illustrates the failure mode of the SD floor expansion joint specimen. During the input of $550 \mathrm{~cm} / \mathrm{s}^{2}$, the cover plate was disengaged from the side plate, creating a gap between floors. Since the cover plate could no longer sustain human weight, its function was lost. Therefore, this damage state was classified as failure. The relative displacement at the timing of failure can be estimated by the response of the strain gauge attached to the cover plate. A large tension force was applied to the cover plate at the moment of failure, as shown in Figure 16(C). From the response of strain gauge F19 attached to the center of the cover plate, this moment was identified as $4.59 \mathrm{~s}$, as shown in Figure 16(D). Note that large peaks in the compression side were observed at F19 due to the cover plate collision with the side plate. From the relative displacement obtained by the D9 transducer, the critical value was calculated as $22.2 \mathrm{~cm}$ (127\% of the design motion range $17.5 \mathrm{~cm})$. This value is similar to the maximum affordable length of $22.6 \mathrm{~cm}$ calculated from the dimension of the cover plate, as shown in Figure 16(C). Therefore, this damage depends on the dimension of the cover plate and is displacement sensitive. In summary, damage state 1 was observed when the relative displacement reached nearly one half of the design tolerance, and the failure occurred at approximately $130 \%$ of the design tolerance. Compared to the HP floor expansion joint specimen, which exhibited damage state 1 at $193 \%$ of the design tolerance, the margin of safety of the SD floor expansion joint is significantly smaller.

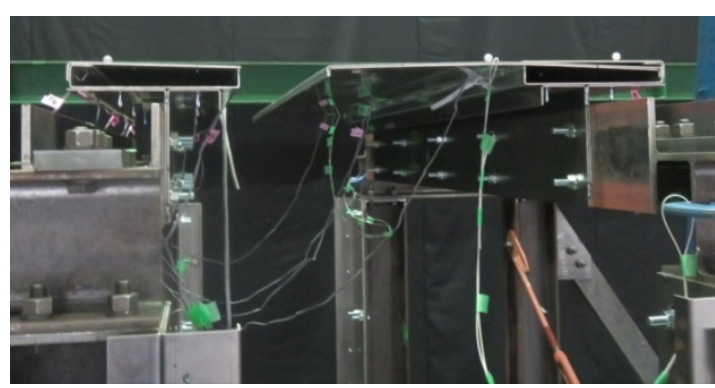

(A)

(1)

(2)

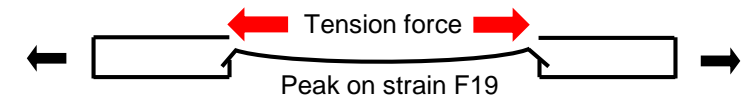

Maximum length $=96+96+17+17=226$

(3)

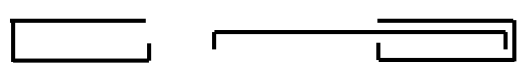

(C)

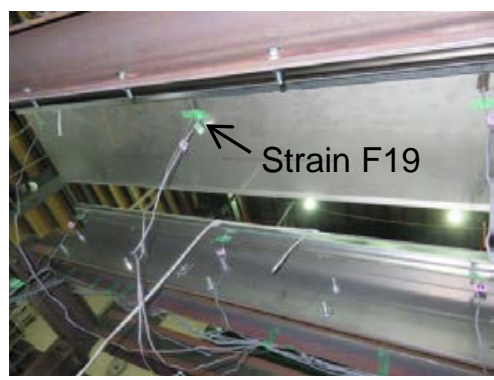

(B)
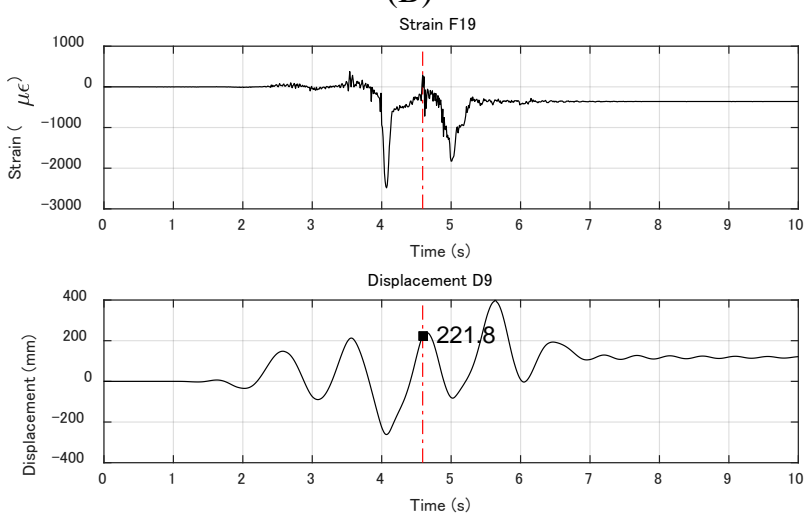

(D)

FIGURE 16 SD floor specimen failure (cover plate disengaged) (unit: $\mathrm{mm}$ ): (A) front view, (B) inside view, (C) damage sequence, and (D) strain and relative displacement response during the excitation of $550 \mathrm{~cm} / \mathrm{s}^{2}$

\subsubsection{SD wall expansion joint "DS1: rubber sheet disengagement"}

Damage state 1 for the SD wall expansion joint specimen was rubber sheet disengagement, as shown in Figure 17. The gap indicated in Figure 17(A) led to concern about air and water leakage. This damage was first observed after the input of 400 $\mathrm{cm} / \mathrm{s}^{2}$. For each wall expansion joint, two rubber sheets at the edges were attached as a sealing material. During excitations, a rubber sheet on one side moved along with the cover plate and was rubbed by the surrounding materials as shown in Figure 17(B). Under $400 \mathrm{~cm} / \mathrm{s}^{2}$, the rubber sheet on the back wall was largely detached, and a gap of approximately $5 \mathrm{~cm}$ was created. This damage resulted from repeated loading during shakings, and therefore it is difficult to identify the critical demand value that initiates this damage. This damage can be repaired by an adjustment and thus was classified as damage state 1 . 


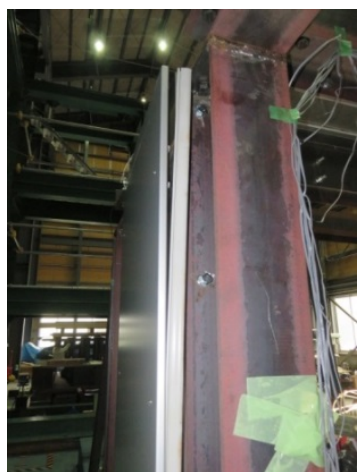

(A)

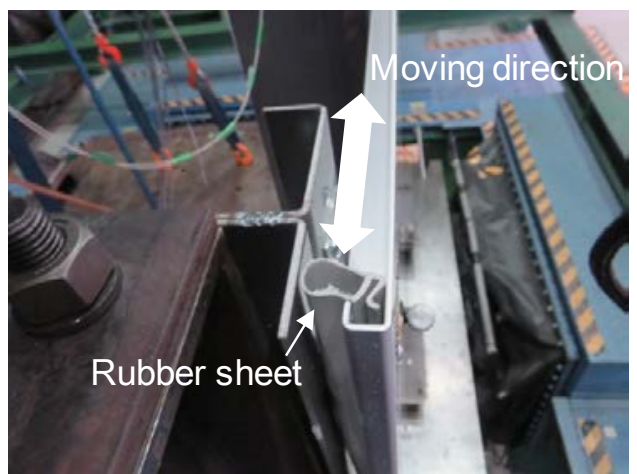

(B)

FIGURE 17 SD wall specimen DS1 (rubber sheet disengagement): (A) gap and (B) deformed rubber sheet

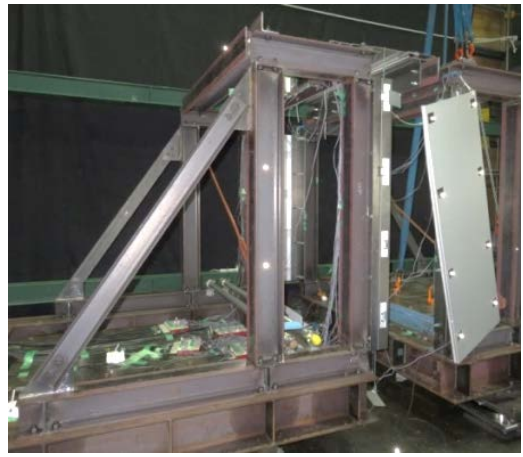

(A)

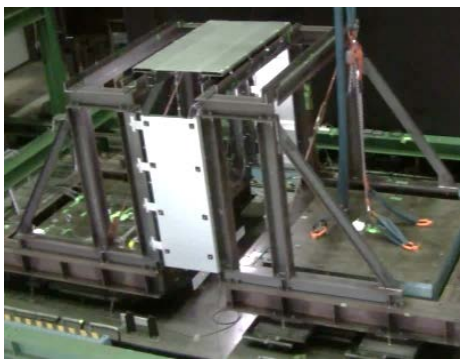

(D)

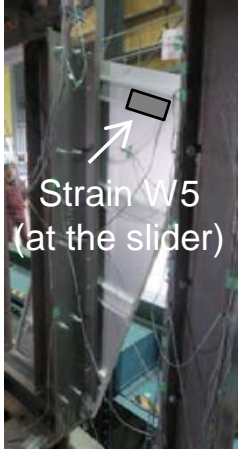

(B)

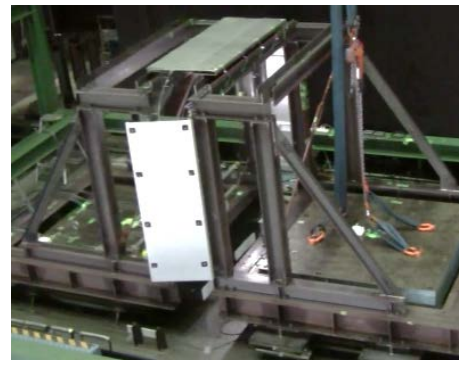

(E)
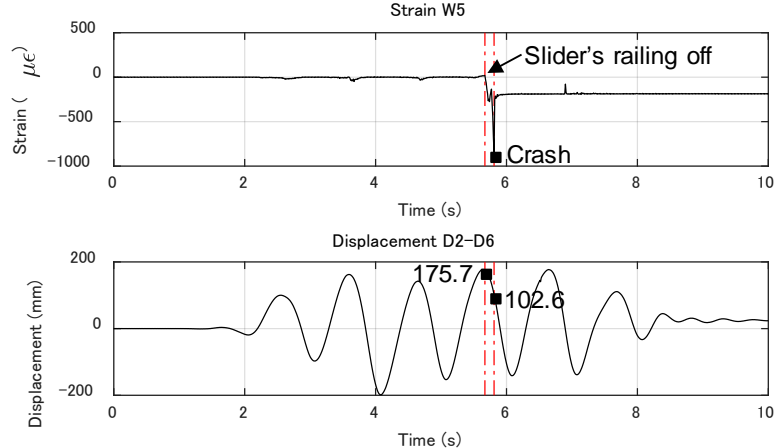

(C)

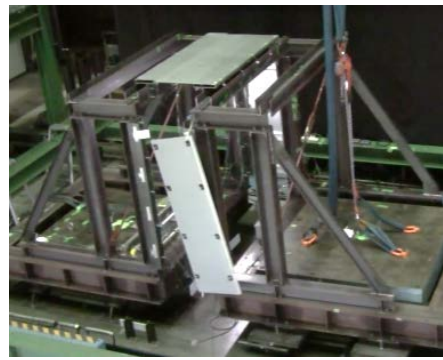

(F)

FIGURE 18 SD wall specimen failure (cover plate dropped off) (unit: $\mathrm{mm}$ ): (A) front view, (B) inside view, (C) strain and relative displacement response during the input of $450 \mathrm{~cm} / \mathrm{s}^{2}$, (D) at the moment when the relative displacement equaled $17.5 \mathrm{~cm},(\mathrm{E})$ at the moment of crash, and (F) immediately after the crash

\subsubsection{SD wall expansion joint "Failure: cover plate dropped off"}

Figures 18(A)-(B) show the failure of the SD wall expansion joint specimen. During the input of $450 \mathrm{~cm} / \mathrm{s}^{2}$, the cover plate of the front wall fell off because its sliders railed off. Immediately after the sliders dropped off, the short-period frame crashed into the cover plate (Figure 18(D)-(F)). This damage sequence can be explained from the strain responses. As shown in Figure 18(C), the response of the strain gauge W5 attached to the slider had a large peak in the compression side. The large compression force was applied when the cover plate was crashed by the short-period frame, and thus the moment at which the sliders railed off should be at the peak in the tension side immediately before the crash. Therefore, the relative displacement at the time of falling was evaluated as $17.6 \mathrm{~cm}$. This result corresponds well with the design motion range, which was defined as a slider length of $17.5 \mathrm{~cm}$. Thus, this damage state was displacement sensitive. Note that under the excitation of $450 \mathrm{~cm} / \mathrm{s}^{2}$, only the cover plate of the front wall dropped off because the relative displacement at the back wall was smaller than that at the front wall due to the rotational movement of the long-period frame.

After the removal of the front wall, a sine wave of $1.0 \mathrm{~Hz}$ with $500 \mathrm{~cm} / \mathrm{s}^{2}$ was input, and the back wall collapsed as well. The critical relative displacement on the back side was measured as $19.0 \mathrm{~cm}$, which was $1.5 \mathrm{~cm}$ larger the motion range. In summary, the margin of safety beyond the design tolerance of the SD wall expansion joint was nearly zero because the cover plate fell off immediately after the relative displacement surpassed the design tolerance.

\section{DISCUSSION OF SAFETY MARGIN}

The relationship between the damage states and the ratio to the design motion range is summarized in Figure 19. The differences in the safety margin beyond the design motion range of the HP and SD expansion joints specimen are significant. The HP expansion joint specimens exhibited only damage state 1 within $200 \%$ of the motion range, whereas the SD expansion 
joints showed damage state 1 within the motion range and failure at approximately $100 \%$ to $130 \%$. Because the safety margin of the HP specimens was sufficient, this section mainly focuses on the SD specimens. Note that "DS1: rubber sheet disengaged" of the SD wall was not dependent on displacement, but the maximum relative displacement under the input of $350 \mathrm{~cm} / \mathrm{s}^{2} \mathrm{was}$ used here because this damage was first observed after $400 \mathrm{~cm} / \mathrm{s}^{2}$.

Between the SD floor and wall expansion joints, the margin of failure beyond the motion range differed because the design motion range of $17.5 \mathrm{~cm}$ is a nominal value that depends on the manufacturer. The motion range can be easily identified from the drawing for some expansion joints (for the SD wall) but not for others (for the HP floor). Some other motion ranges are determined by the critical length, i.e., the collision length, plus a safety margin (for the HP wall and SD floor). Thus, the safety margin considered in the design motion range differs by manufacturer and type. For the SD wall expansion joint, the safety margin was zero, and failure occurred immediately after the motion range.

Manufacturers should include at least some extent of safety margin in the nominal motion range, especially for expansion joints that are difficult to repair and whose damage may hurt people on the ground, such as wall expansion joints. For example, as seen in the tested SD floor expansion joint, a safety margin of at least $30 \%$ beyond the motion range is recommended to guarantee the performance expected from the drawing.

In addition, in the selection of expansion joints, some safety factors (i.e., clearance $=$ minimum separation distance $\times$ safety factor) are considered voluntarily by structural designers. To consider appropriate safety factors, the designer should carefully check the deformation mechanism in the drawing and evaluate the amount of safety margin assumed in the nominal motion range set by the expansion joint manufacturers. If there is no safety margin in the nominal motion range, as is the case for the SD wall expansion joint, or no information is available, the designers should consider extending the clearance by a sufficient safety factor to guarantee the motion range of expansion joints for the targeted hazard level. The above statement can be applied when expansion joints are used at a sky bridge connecting adjacent buildings or at a pedestrian bridge. If adjacent buildings are directly connected by expansion joints at a dense city area, a sufficient large clearance between adjacent buildings might not be easy to achieve and the use of HP expansion joints could be an option.

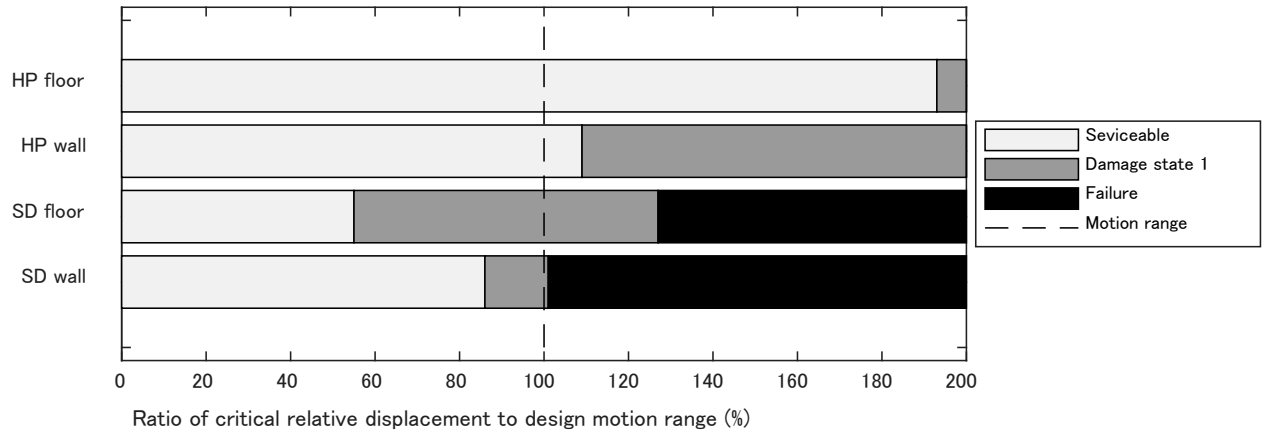

\section{FIGURE 19 Relationship between the damage states and the ratio of the critical relative displacement to the design motion range}

\section{REPAIR INFORMATION}

Information on repair cost, time and procedures for each damage state of components is indispensable for building owners to estimate the required cost and downtime in the event of a disaster. In this experiment, we asked an expansion joint manufacturer to participate in the test and observe a sequence of damage with us. A questionnaire was used to obtain repair information for each damage state of the tested expansion joints.

The repair information shown in Table 4 includes 1) repair procedures, 2) replacement materials for expansion joints, 3) replacement materials for indirect materials such as finishing, 4) working hours with the number of workers, 5) material costs for the replacement of damaged expansion joint parts, and 6) construction costs for the replacement of damaged expansion joint parts. The cost is expressed as the ratio of the initial material or installation cost for expansion joints. For the estimation of construction cost for repair, it is assumed that the expansion joints are set on a passage between two buildings at a height of $20 \mathrm{~m}$ above the ground. Note that the original material cost for each of expansion joints was JPY 255,000 (USD 2,550) for the HP floor, JPY 220,000 (USD 2,200) for the HP wall, JPY 185,000 (USD 1,850) for the SD floor, and JPY 110,000 (USD 1,100 ) for the SD wall. The installation cost of each expansion joint was JPY 150,000 (USD 1,500) for reference.

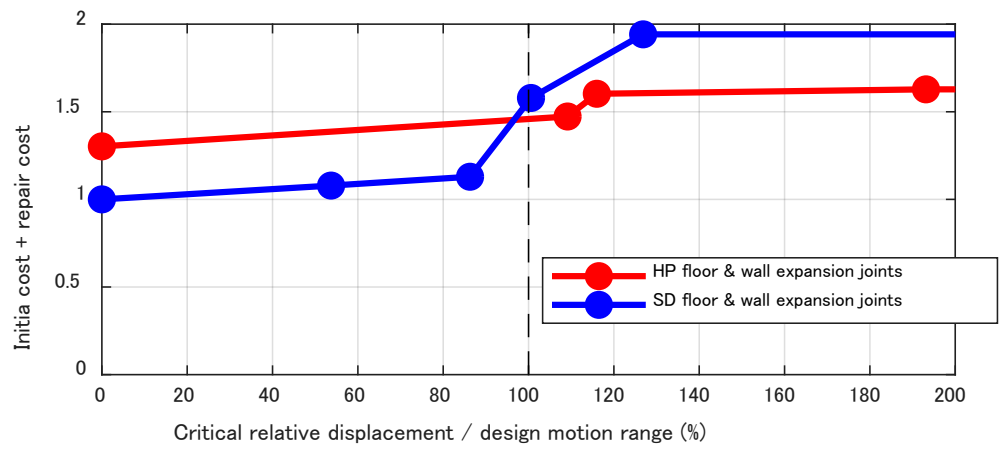

FIGURE 20 Comparison of the sum of the initial cost and repair cost for HP and SD expansion joints 
As an example to evaluate the tendency of the cost for expansion joints, the sum of the initial cost and repair cost for the sets of wall and floor expansion joints against the peak relative displacement were calculated based on Table 4 and presented in Figure 20. Each cost was normalized by the initial cost of the SD wall and floor expansion joints, which was JPY 595,000 (USD 5,950). A tendency was observed that even though the initial cost of the HP expansion joints is 1.3 times higher than that for the SD expansion joints, the sum of the initial cost and repair cost of the SD expansion joints exceeds that of the HP expansion joints after the relative displacement exceeds the motion range of the expansion joints. The presented cost evaluation can be used as one reference, but uncertainty must be taken into account in a probabilistic way to achieve a more reliable evaluation.

The presented information will be useful to structural engineers and owners of buildings in the selection of expansion joints. With information on repair and safety margins, designers and owners of buildings can select expansion joints based on each interest, such as cheap initial cost, cheap life cycle cost, or high safety margin considering the continuity of building use.

\section{CONCLUSIONS}

This paper identified damage mechanisms and safety margin of expansion joints through a series of shaking table tests. Among a wide range of ranks and deformation mechanisms of expansion joints, four commonly used expansion joints, highperformance (HP) and standard (SD) for floor and wall, were selected. The expansion joints were installed between two steel frames with different natural periods of $0.46 \mathrm{~s}$ and $6.0 \mathrm{~s}$. As inputs, ground motions and a sine wave of $1.0 \mathrm{~Hz}$ were used considering experimental limitations. The wave amplitude was increased from $300 \mathrm{~cm} / \mathrm{s}^{2}$ until expansion joint failure. The notable findings are as follows:

1. A total of seven damage patterns of the four expansion joint specimens were observed. The damage mechanisms and relative displacements at the moment of damage were identified with the aid of strain gauges attached near the collision and damage locations. By comparing the relative displacement obtained at the timing of strain peaks with the expected collision length in the design paper, most of the damage patterns were confirmed as displacement dependent.

2. The difference in the safety margin beyond the design motion range between HP and SD expansion joint specimens is significant. The HP floor specimen showed damage state 1 at $190 \%$ of the design motion range of $17.5 \mathrm{~cm}$, whereas the SD floor specimen exhibited damage state 1 at approximately $50 \%$ and the failure state at $130 \%$. Two different patterns of damage state 1 for the HP wall specimen were observed at $110 \%$ to $130 \%$, whereas the SD wall specimen failed at exactly $100 \%$ of the motion range.

3. The safety margin in the nominal design motion range differs by manufacturer and type. For the SD wall expansion joint, failure immediately after the motion range should be avoided and at least $30 \%$ of the safety margin is recommended as is the case of the SD floor expansion joint. Considering the difference in the safety margin in the nominal design motion range, structural designers are encouraged to assess the amount of safety margin from the drawing papers and take it into account in the selection of expansion joints. When no information on the safety margin is available, designers should consider extending the clearance by a sufficient safety factor to guarantee the motion range of the expansion joints for the targeted hazard level.

4. For each damage state, information on repair procedures and cost was obtained through a questionnaire to an expansion joint manufacturer. To provide readers with a sense of cost assessment, the sum of the initial cost and repair cost of the HP and SD expansion joints regarding the peak relative displacement was calculated. The initial cost of the HP was 1.3 times higher than that of the SD, but the sum of the initial cost and repair cost for the SD became higher than that of the HP after the relative displacement exceeds the motion range of the expansion joints. The designer and owner can refer this information in the selection of expansion joints.

The test results revealed that damage to expansion joints depends on the relative displacement between two systems. According to [FEMA 2012], fragility functions for displacement-sensitive damage can be determined by assuming the expected damage length from design papers and the construction tolerance. Therefore, based on the test results, it should be possible to construct fragility functions for expansion joints with appropriate assumptions, which remains for future work. By developing fragility functions, the sum of the initial cost and repair cost of the HP and SD expansion joints can be compared in a probabilistic manner.

\section{ACKNOWLEDGMENTS}

The present work is partially supported by the Tokyo Metropolitan Resilience Project of the National Research Institute for Earth Science and Disaster Resilience (NIED) (subproject C, subject 3 leader: Masahiro Kurata). Sincere appreciation is offered to Nippon Steel \& Sumikin Engineering Co., Ltd. for providing materials for the shaking table tests. The authors also thank Niitakaseisakusho Co., Ltd. and Takenaka Corporation for their technical support of the tests.

\section{REFERENCES}

1. Kasai K, Mita A, Kitamura H, Matsuda K, Morgan T, Taylor A. Performance of Seismic Protection Technologies during the 2011 Tohoku-Oki Earthquake. Earthquake Spectra. 2013; 29(1): 265-293.

2. National Institute for Land and Infrastructure Management (NILIM )and Building Research Institute (BRI). Quick Report of the Field Survey on the Building Damage by the 2016 Kumamoto Earthquake. Technical Note of NILIM No. 929 and Building Research Data No. 173, Tokyo, JAPAN, 2016. (in Japanese) 
3. Bertero V V. Observations of structural pounding. Proceedings of the International Conference on the Mexico Earthquake 1985: Factors Involved and Lessons Learned; September 19-21, 1986; Mexico City, Mexico.

4. Filiatrault A, Cervantes M, Folz B, Prion H. Pounding of buildings during earthquakes: a Canadian perspective. Canadian Journal of Civil Engineering. 1994; 21(2): 251-265.

5. Kasai K, Maison B F. Building Pounding Damage During the 1989 Loma Prieta Earthquake. Engineering Structures. 1997; 19(3): 195-207.

6. Public Works Research Institute (PWRI), Report on the disaster caused by the 1995 Hyogoken Nanbu Earthquake. Journal of Research. 1997; 33.

7. Cole L G, Dhakal P R, Turner M F. Building pounding damage observed in the 2011 Christchurch earthquake. Earthquake Engng Struc Dyn. 2012; 41: 893-913.

8. Federal Emergency Management Agency (FEMA). P-58 Next-generation Seismic Performance Assessment for Buildings, Volume 1 - Methodology, FEMA, Washington, D.C., USA, 2012.

9. Malhotra PK. Dynamics of seismic pounding at expansion joints of concrete bridges. J Eng Mech (ASCE). 1998; 124:794802.

10. Ni Y Q, Hua X G, Wong K Y, and Ko J M. Assessment of bridge expansion joints using long-term displacement and temperature measurement. J Perform Constr Facil (ASCE). 2007; 21(2): 143-151.

11. Bi K, Hao H, Chouw N. Required separation distance between decks and at abutments of a bridge crossing a canyon site to avoid seismic pounding. Engng Struc Dyn. 2010; 39: 303-323.

12. McCarthy E, Wright T, Padgett E J, DesRoches R, Bradford P. Development of an Experimentally Validated Analytical Model for Modular Bridge Expansion Joint Behavior. J Bridge Eng (ASCE). 2014; 19(2): 235-244.

13. Sun Z, Zhange Y. Failure Mechanism of Expansion Joints in a Suspension Bridge. J Bridge Eng (ASCE). 2016; 21(10): 1-1

14. National Institute for Land and Infrastructure Management (NILIM) and Building Research Institute (BRI). Report on Field Surveys and Subsequent Investigations of Building Damage Following the 2011 off the Pacific coast of Tohoku Earthquake, Technical Note of NILIM No. 674 and Building Research Data No. 136, Tokyo, JAPAN, 2012. (in Japanese)

15. Takabatake H, Yasui M, Nakagawa Y, Kishida A. Relaxation method for pounding action between adjacent buildings at expansion joints. Earthquake Engng Struc Dyn. 2014; 43: 1381-1400.

16. Japan Expansion Joint Association (JEJA). Guideline of Expansion Joints for Buildings. JEJA, Tokyo, JAPAN, 2016. (in Japanese)

17. Building Center of Japan (BCJ). Criteria for Structural Calculation for Buildings Split by Expansion Joints, Building letter, 2008; 506. (in Japanese)

18. International Conference of Building Officials (ICBO). Uniform Building Code. ICBO, Whittier, CA, USA, 1997.

19. European Committee for Standardization (CEN). European Standard EN 1998-1: 2005 Eurocode 8: Design of structures for earthquake resistance. Part 1: General rules, Seismic action and rules for buildings. European Committee for Standardization: Brussels, Belgium, 2005.

20. Construction and Planning Administration Ministry of Interior. Seismic Provisions. Building Code (TBC): Taipei, Taiwan, 1997.

21. Japanese Society of Seismic Isolation (JSSI). Guideline on Expansion Joints for Seismic Isolation buildings. JSSI, Tokyo, JAPAN, 2013. (in Japanese)

22. Disaster Prevention Research Institute, Kyoto University. Introduction of Strong Earthquake Response Simulator. available at http://kyoyo.dpri.kyoto-u.ac.jp/en/introduction.html. [last accessed March 2018]

23. Ponzo F C, Di Cesare A, Leccese G, and Nigro D. Shake table testing on restoring capability of double concave friction pendulum seismic isolation systems. Earthquake Engng Struc Dyn. 2017; 46: 2337-2353.

24. National Institute for Earth Science and Disaster Resilience. Strong-motion Seismograph Networks (K-NET, KiK-net), available at http://www.kyoshin.bosai.go.jp/. [last accessed April 6 2018]

25. Japan Meteorological Agency. Strong motion records, available at http://www.data.jma.go.jp/svd/eqev/data/kyoshin/jishin/hyogo_nanbu/index.html [last accessed April 6 2018]

26. The Building Center of Japan (BCJ), BCJ artificial waves, available at https://www.bcj.or.jp/download/wave.html [last accessed April 6 2018]

27. Nishimoto K, Nakamura H, Hasegawa H, Wakita N. Bearing Stress and Velocity Dependency of Spherical Sliding Bearing through Large-scale Tests. Technical summary of the Architectural Institute of Japan annual research meeting. 2016; 405: 445-446. (in Japanese)

28. Architectural Institute of Japan (AIJ). Recommendation for Aseismic Design and Construction of Nostructural Elements. AIJ, Tokyo, 2003. (in Japanese)

29. Anagnostopoulos S. Pounding of buildings in series during earthquake. Earthquake Engng Struc Dyn. 1988 ; 16: $443-456$.

30. Porter K, Kennedy R, Bachman R. Creating Fragility Functions for Performance-Based Earthquake Engineering. Earthquake Spectra. 2007; 23(2): 471-489. 
TABLE 4 Repair information for each damage state of expansion joints (EXPJ) obtained from a questionnaire to an expansion joint manufacturer

\begin{tabular}{|c|c|c|c|c|c|c|c|}
\hline & HP floor & \multicolumn{2}{|c|}{ HP wall } & \multicolumn{2}{|c|}{ SD floor } & \multicolumn{2}{|c|}{ SD wall } \\
\hline & $\begin{array}{c}\text { DS1 } \\
\text { Cover Plate } \\
\text { Disengaged }\end{array}$ & $\begin{array}{c}\text { DS1-A } \\
\text { Spring Deformation }\end{array}$ & $\begin{array}{c}\text { DS1-B } \\
\text { Screw Rupture }\end{array}$ & $\begin{array}{c}\text { DS1 } \\
\text { Screw Rupture }\end{array}$ & $\begin{array}{c}\text { Failure } \\
\text { Cover Plate } \\
\text { Disengaged }\end{array}$ & $\begin{array}{c}\text { DS1 } \\
\text { Rubber Sheet } \\
\text { Disengaged }\end{array}$ & $\begin{array}{c}\text { Failure } \\
\text { Cover Plate } \\
\text { Dropped Off }\end{array}$ \\
\hline $\begin{array}{c}\text { Repair } \\
\text { procedure }\end{array}$ & $\begin{array}{l}\text { Reset cover plate, } \\
\text { and change floor } \\
\text { finishing if needed. }\end{array}$ & $\begin{array}{l}\text { Change damaged } \\
\text { springs from } \\
\text { outside after } \\
\text { assembling } \\
\text { scaffolds, and re- } \\
\text { inject caulking. }\end{array}$ & $\begin{array}{l}\text { Re-hit screws from } \\
\text { outside after } \\
\text { assembling } \\
\text { scaffolds, and re- } \\
\text { inject caulking for } \\
\text { surrounding } \\
\text { materials. }\end{array}$ & $\begin{array}{l}\text { Re-hit screws from } \\
\text { inside. }\end{array}$ & $\begin{array}{l}\text { Change cover plate, } \\
\text { screws, and floor } \\
\text { finishing from } \\
\text { inside. Remove a } \\
\text { part of the inner } \\
\text { wall expansion } \\
\text { joints and inner wall } \\
\text { finishing. }\end{array}$ & $\begin{array}{l}\text { Reset rubber sheet } \\
\text { from outside by a } \\
\text { vehicle for work at } \\
\text { height. }\end{array}$ & $\begin{array}{l}\text { Install cover plate } \\
\text { and attach } \\
\text { members from } \\
\text { outside after } \\
\text { assembling } \\
\text { scaffolds. }\end{array}$ \\
\hline $\begin{array}{c}\text { Replacement } \\
\text { of EXPJ } \\
\text { material }\end{array}$ & Not required & 3 springs & Screws & Screws & Cover plate & Not required & All \\
\hline $\begin{array}{c}\text { Replacement } \\
\text { of indirect } \\
\text { material }\end{array}$ & Floor finishing & Caulking & Caulking & Not required & $\begin{array}{l}\text { Floor and inner wall } \\
\text { finishing, and inner } \\
\text { wall EXPJ }\end{array}$ & Not required & Caulking \\
\hline $\begin{array}{l}\text { Working } \\
\text { hours }\end{array}$ & $\begin{array}{c}1 \text { day } \\
\text { by } 2 \text { workers }\end{array}$ & $\begin{array}{c}1 \text { day } \\
\text { by } 2 \text { workers }\end{array}$ & $\begin{array}{c}1 \text { day } \\
\text { by } 2 \text { workers }\end{array}$ & $\begin{array}{c}1 \text { day } \\
\text { by } 2 \text { workers }\end{array}$ & $\begin{array}{c}2 \text { days } \\
\text { by } 2 \text { workers }\end{array}$ & $\begin{array}{c}0.5 \text { day } \\
\text { by } 2 \text { workers }\end{array}$ & $\begin{array}{c}2.5 \text { day } \\
\text { by } 2 \text { workers }\end{array}$ \\
\hline $\begin{array}{c}\text { EXPJ } \\
\text { material cost }\end{array}$ & Not required & $\begin{array}{l}12 \% \text { of the } \\
\text { original EXPJ cost }\end{array}$ & $\begin{array}{l}1 \% \text { of the } \\
\text { original EXPJ cost }\end{array}$ & $\begin{array}{l}1 \% \text { of the } \\
\text { original EXPJ cost }\end{array}$ & $\begin{array}{l}61 \% \text { of the } \\
\text { original EXPJ cost }\end{array}$ & Not required & $\begin{array}{l}100 \% \text { of the } \\
\text { original EXPJ cost }\end{array}$ \\
\hline $\begin{array}{c}\text { Construction } \\
\text { cost }\end{array}$ & $\begin{array}{c}\text { Subtle } \\
\text { (assume } 10 \% \text { of the } \\
\text { initial installation } \\
\text { cost for EXPJ) }\end{array}$ & $\begin{array}{l}50 \% \text { of the } \\
\text { initial installation } \\
\text { cost for EXPJ }\end{array}$ & $\begin{array}{l}50 \% \text { of the } \\
\text { initial installation } \\
\text { cost for EXPJ }\end{array}$ & $\begin{array}{l}30 \% \text { of the } \\
\text { initial installation } \\
\text { cost for EXPJ }\end{array}$ & $\begin{array}{l}100 \% \text { of the } \\
\text { initial installation } \\
\text { cost for EXPJ }\end{array}$ & $\begin{array}{c}20 \% \text { of the } \\
\text { initial installation } \\
\text { cost for EXPJ }\end{array}$ & $\begin{array}{c}125 \% \text { of the } \\
\text { initial installation } \\
\text { cost for EXPJ }\end{array}$ \\
\hline
\end{tabular}

The assembling of scaffolds is assumed to be finished in one day. 